\title{
Scaffold Hopping to Imidazo[1,2-a]pyrazin-8-one Positive Allosteric Modulators of Metabotropic Glutamate 2 Receptor
}

\author{
Ana I. de Lucas, ${ }^{\ddagger}$ Juan A. Vega, $\$$ Aránzazu García Molina, $\neq$ María Lourdes Linares, $\$$ Gary \\ Tresadern, ${ }^{\S}$ Hilde Lavreysen," Daniel Oehlrich," Andrés A. Trabanco and José M. Cid" \\ * Discovery Chemistry, Discovery Sciences, Janssen Research \& Development, Division of Janssen-Cilag S.A., \\ Jarama 75A, Toledo 45007, Spain, \$Computational Chemistry, Discovery Sciences, Janssen Research \& \\ Development, Division of Janssen Pharmaceutica N.V., Turnhoutseweg 30, B-2340 Beerse, "Discovery Chemistry, \\ Discovery Sciences, Janssen Research \& Development, Division of Janssen Pharmaceutica N.V. Turnhoutseweg 30, \\ B-2340 Beerse.'Clinical Research and Development, Janssen Pharmaceutica N.V., Turnhoutseweg 30, B-2340 Beerse, \\ Belgium
}

Corresponding Author

*for J.M.C: phone, +34 925 245767; e-mail: jcid@its.jnj.com.

\section{Supporting Information}

\section{Table of contents:}

Experimental procedures

S2-S24

Analytical methods

S25-S27

Biochemical assay

S28-S29

Selectivity panel

S30-S31

\section{Experimental procedures}

Unless otherwise noted, all reagents and solvents were obtained from commercial suppliers and used without further purification. Thin layer chromatography (TLC) was carried out on silica gel 60 F254 plates (Merck). Flash column chromatography was performed on silica gel, particle size 
$60 \AA$, mesh of 230-400 (Merck) under standard techniques. Microwave assisted reactions were performed in a single-mode reactor, Biotage Initiator Sixty microwave reactor (Biotage), or in a multimode reactor, MicroSYNTH Labstation (Milestone, Inc.). Nuclear magnetic resonance (NMR) spectra were recorded with either a Bruker DPX-400 or a Bruker AV-500 spectrometer (Bruker AG) with standard pulse sequences, operating at 400 and $500 \mathrm{MHz}$, respectively, using $\mathrm{CDCl}_{3}$ and DMSO- $\mathrm{d}_{6}$ as solvents. Chemical shifts $(\delta)$ are reported in parts per million (ppm) downfield from tetramethylsilane $(\delta=0)$. Coupling constants are reported in hertz. Splitting patterns are defined by s (singlet), d (doublet), dd (double doublet), $t$ (triplet), $q$ (quartet), quin (quintet), sex (sextet), sep (septet), or m (multiplet).

Liquid chromatography combined with mass spectrometry (LCMS) was performed using either an HP 1100 HPLC system (Agilent Technologies, Waldbronn, Germany) or an Acquity UPLC system (Waters, Milford, MA, USA) comprising an LC pump (quaternary or binary) with degasser, an autosampler, a column oven, a diode array detector (DAD), and a column as specified in the respective methods. Flow from the column was brought to the MS spectrometer. The MS detector (either SQD or TOF) was configured with an atmospheric pressure ion source. Nitrogen was used as the nebulizer gas. Data acquisition was performed with MassLynx Openlynx software or with Chemsation-Agilent data browser software.

Melting point values are peak values and were obtained with experimental uncertainties that are commonly associated with this analytical method. Melting points were determined in open capillary tubes on either a Mettler FP62 (A) or a Mettler FP 81HT/ FP90 (B) apparatus with a temperature gradient of $10{ }^{\circ} \mathrm{C} / \mathrm{min}$. Maximum temperature was $300^{\circ} \mathrm{C}$.

Purities of all new compounds were determined by analytical reverse phase RP HPLC or RP UPLC coupled to a mass spectrometry detector, using the area percentage method on the UV trace 
scanning from 200 to $450 \mathrm{~nm}$, and compounds were found to have $\geq 95 \%$ purity unless otherwise specified.

\section{7-butyl-2-methyl-3-[(4-phenyl-1-piperidyl)methyl]imidazo[1,2-a]pyrazin-8-one (3a).}

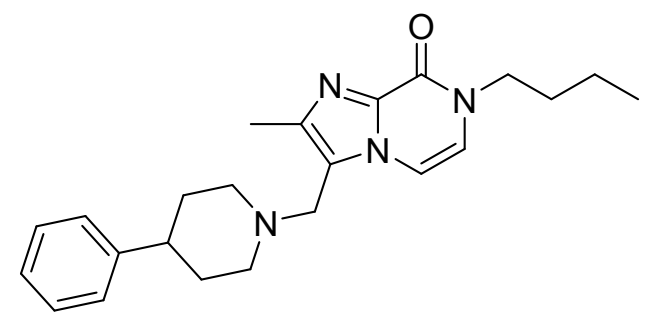

Sodium triacetoxyborohydride $(0.243 \mathrm{~g}, 1.14 \mathrm{mmol})$ was added to a solution of intermediate 9 $(0.18 \mathrm{~g}, 0.76 \mathrm{mmol})$ and 4-phenylpiperidine $(0.15 \mathrm{~g}, 0.915 \mathrm{mmol})$ in DCE $(30 \mathrm{~mL})$ at rt. The mixture was stirred at rt for $3 \mathrm{~h}$. The crude was treated with $\mathrm{DCM}$ and saturated solution of $\mathrm{NaHCO}_{3}$ and the reaction mixture was extracted with DCM. The organic layer was separated, washed with brine, dried $\left(\mathrm{Na}_{2} \mathrm{SO}_{4}\right)$, filtered and concentrated in vacuo. The residue thus obtained was purified by flash chromatography (silica, $7 \mathrm{~N} \mathrm{NH}_{3}$ in $\mathrm{MeOH} / \mathrm{DCM}$ from $0 / 100$ to 10/90). The desired fractions were collected and concentrated in vacuo to yield $3 \mathbf{a}(0.08 \mathrm{~g}, 28 \%)$ as a light brown solid. LC-MS m/z: calculated for $\mathrm{C}_{23} \mathrm{H}_{30} \mathrm{~N}_{4} \mathrm{O}[\mathrm{M}+\mathrm{H}]+379.20$ found $379.23[\mathrm{M}+\mathrm{H}]+.{ }^{1} \mathrm{H}$ NMR $\left(500 \mathrm{MHz}, \mathrm{CDCl}_{3}\right)$ $\delta$ ppm $7.35(\mathrm{~d}, J=5.8 \mathrm{~Hz}, 1 \mathrm{H}) 7.27-7.32(\mathrm{~m}, 2 \mathrm{H}) 7.16-7.23(\mathrm{~m}, 3 \mathrm{H}) 6.59(\mathrm{~d}, J=5.8 \mathrm{~Hz}, 1 \mathrm{H})$ $3.95(\mathrm{t}, J=7.4 \mathrm{~Hz}, 2 \mathrm{H}) 3.65(\mathrm{~s}, 2 \mathrm{H}) 2.93(\mathrm{br} \mathrm{d}, J=11.3 \mathrm{~Hz}, 2 \mathrm{H}) 2.52(\mathrm{tt}, J=12.1,3.6 \mathrm{~Hz}, 1 \mathrm{H}) 2.39$ (s, $3 \mathrm{H}) 2.12(\mathrm{td}, J=11.6,1.7 \mathrm{~Hz}, 2 \mathrm{H}) 1.84(\mathrm{br} \mathrm{d}, J=12.7 \mathrm{~Hz}, 2 \mathrm{H}) 1.63-1.78(\mathrm{~m}, 4 \mathrm{H}) 1.39$ (dq, $J=15.2,7.5 \mathrm{~Hz}, 2 \mathrm{H}) 0.95(\mathrm{t}, J=7.4 \mathrm{~Hz}, 3 \mathrm{H})$.

\section{General Method (Suzuki-Miyaura coupling); synthesis of imidazo[1,2-a] pyridines 3b-i}




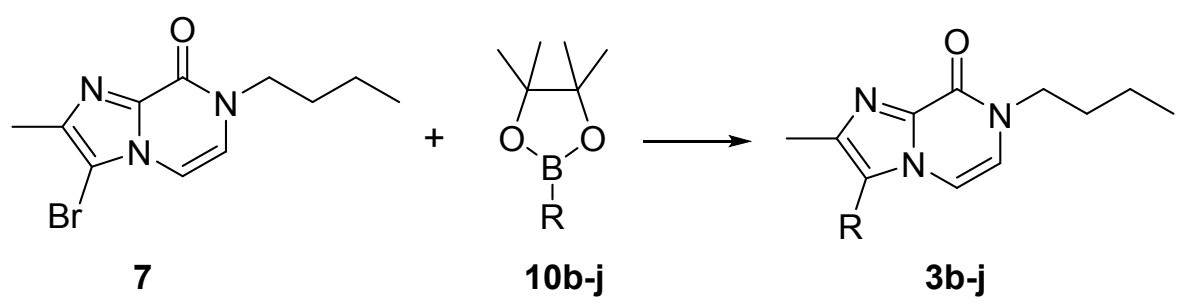

\section{Synthesis of 7-butyl-3-[3-fluoro-4-[(2-methyl-4-pyridyl)oxy]phenyl]-2-methyl-imidazo[1,2- a]pyrazin-8-one (3b).}

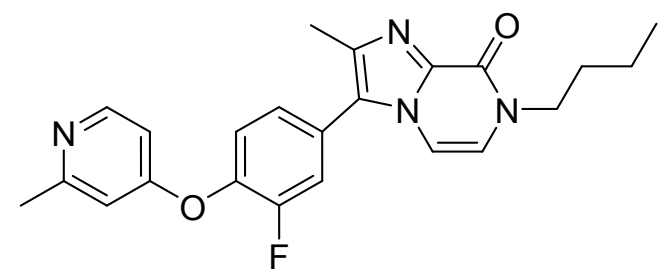

Tetrakis(triphenylphosphine)palladium $(0.08 \mathrm{~g}, 0.07 \mathrm{mmol})$, was added to a deoxygenated and stirred suspension of 7 (0.2 g, $0.704 \mathrm{mmol}), 2$-methyl-[2-fluoro-4-(4,4,5,5-tetramethyl-1,3,2dioxaborolan-2-yl)phenoxy]-pyridine (0,324 g, $0.98 \mathrm{mmol}$; C.A.S. 1200124-19-1) in a mixture of $\mathrm{NaHCO}_{3}(1.5 \mathrm{~mL})$ and dioxane $(3 \mathrm{~mL})$ at $\mathrm{rt}$ under Nitrogen. The mixture was heated under $\mathrm{MW}$ irradiation at $150{ }^{\circ} \mathrm{C}$ for 10 min. The crude was diluted with saturated solution of $\mathrm{NaHCO}_{3}$ and extracted with DCM. The organic layer was separated, washed with brine, separated, dried $\left(\mathrm{Na}_{2} \mathrm{SO}_{4}\right)$, filtered and concentrated in vacuo. The residue thus obtained was purified by flash chromatography (silica, $\mathrm{MeOH}-\mathrm{NH}_{3} / \mathrm{DCM}$ from $0 / 100$ to $4 / 96$ ). The desired fractions were collected and concentrated in vacuo to yield $\mathbf{3 b}(0.15 \mathrm{~g}, 52 \%)$ as a pale brown solid. LC-MS m/z: calculated for $\mathrm{C}_{23} \mathrm{H}_{23} \mathrm{FN}_{4} \mathrm{O}_{2}[\mathrm{M}+\mathrm{H}]+407.18$ found $407.21[\mathrm{M}+\mathrm{H}]+.{ }^{1} \mathrm{H}$ NMR (400 MHz, $\mathrm{CDCl}_{3}$ ) $\delta$ ppm $8.41(\mathrm{~d}, J=5.8 \mathrm{~Hz}, 1 \mathrm{H}) 7.22-7.37(\mathrm{~m}, 3 \mathrm{H}) 7.02(\mathrm{~d}, J=6.0 \mathrm{~Hz}, 1 \mathrm{H}) 6.78(\mathrm{~d}, J=2.3 \mathrm{~Hz}, 1$ H) $6.73(\mathrm{dd}, J=5.7,2.4 \mathrm{~Hz}, 1 \mathrm{H}) 6.63(\mathrm{~d}, J=6.0 \mathrm{~Hz}, 1 \mathrm{H}) 3.98(\mathrm{t}, J=7.4 \mathrm{~Hz}, 2 \mathrm{H}) 2.55(\mathrm{~s}, 3 \mathrm{H}) 2.47$ (s, $3 \mathrm{H}) 1.70-1.81(\mathrm{~m}, 2 \mathrm{H}) 1.40(\mathrm{dq}, J=15.1,7.4 \mathrm{~Hz}, 2 \mathrm{H}) 0.96(\mathrm{t}, J=7.3 \mathrm{~Hz}, 3 \mathrm{H})$. 


\section{Synthesis of 7-butyl-3-[4-[(2,6-dimethyl-4-pyridyl)oxy]-3-fluoro-phenyl]-2-methyl-}

imidazo[1,2-a]pyrazin-8-one (3c).

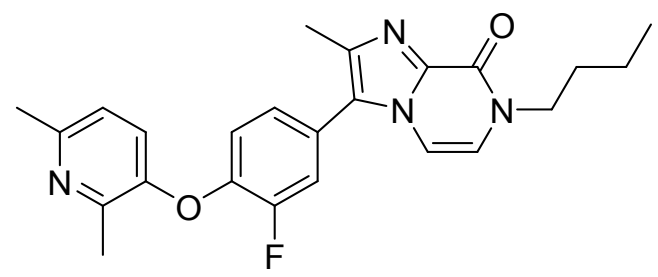

This reaction was carried out according to the procedure described for $\mathbf{3 b}$ using the following: Tetrakis(triphenylphosphine)palladium (0.08 g, $0.069 \mathrm{mmol}), 7$ (0.196 g, $0.69 \mathrm{mmol}), 2,6-$ dimethyl-3-[2-fluoro-4-(4,4,5,5-tetramethyl-1,3,2-dioxaborolan-2-yl)phenoxy]pyridine (0.331 g, 0.966 mmol; C.A.S. 1056461-94-9) in a mixture of $\mathrm{NaHCO}_{3}(1.5 \mathrm{~mL})$ and dioxane $(3 \mathrm{~mL})$. This reaction yielded 3c $(0.145 \mathrm{~g}, 50 \%)$ as white solid LC-MS m/z: calculated for $\mathrm{C}_{24} \mathrm{H}_{25} \mathrm{FN}_{4} \mathrm{O}_{2}$ $[\mathrm{M}+\mathrm{H}]+421.19$ found $421.20[\mathrm{M}+\mathrm{H}]+.{ }^{1} \mathrm{H} \mathrm{NMR}\left(400 \mathrm{MHz}, \mathrm{CDCl}_{3}\right) \delta \mathrm{ppm} 7.23-7.28(\mathrm{~m}, 1 \mathrm{H})$ $7.15(\mathrm{~d}, J=8.1 \mathrm{~Hz}, 1 \mathrm{H}) 7.07$ - $7.12(\mathrm{~m}, 1 \mathrm{H}) 7.02$ (d, J=8.1 Hz, $1 \mathrm{H}) 6.92-7.00(\mathrm{~m}, 2 \mathrm{H}) 6.60$ (d, $J=6.0 \mathrm{~Hz}, 1 \mathrm{H}) 3.97(\mathrm{t}, J=7.4 \mathrm{~Hz}, 2 \mathrm{H}) 2.55(\mathrm{~s}, 3 \mathrm{H}) 2.54(\mathrm{~s}, 3 \mathrm{H}) 2.43(\mathrm{~s}, 3 \mathrm{H}) 1.69-1.79(\mathrm{~m}, 2 \mathrm{H})$ 1.39 (dq, $J=15.2,7.4 \mathrm{~Hz}, 2 \mathrm{H}) 0.95$ (t, $J=7.3 \mathrm{~Hz}, 3 \mathrm{H})$.

Synthesis of 7-butyl-3-[4-[(6-methoxy-3-pyridyl)methylamino]phenyl]-2-methylimidazo[1,2-a]pyrazin-8-one (3d).<smiles>CCCCn1ccn2c(-c3ccc(NCc4ccc(OC)nc4)cc3)c(C)nc2c1=O</smiles> 
This reaction was carried out according to the procedure described for $\mathbf{3 b}$ using the following: Tetrakis(triphenylphosphine)palladium $(0.030 \mathrm{~g}, 0.0264 \mathrm{mmol}), 7(0.150 \mathrm{~g}, 0.528 \mathrm{mmol}), 2-$ methoxy-5-[4-(4,4,5,5-tetramethyl-1,3,2-dioxaborolan-2-yl)phenylaminomethyl]pyridine $(0.197$ g, $0.581 \mathrm{mmol})$ in a mixture of $\mathrm{NaHCO}_{3}(1 \mathrm{~mL})$ and dioxane $(4 \mathrm{~mL})$. This reaction yielded $\mathbf{3 d}$ $(0.181 \mathrm{~g}, 65 \%)$ as pale yellow solid. LC-MS m/z: calculated for $\mathrm{C}_{24} \mathrm{H}_{27} \mathrm{~N}_{5} \mathrm{O}_{2} \quad[\mathrm{M}+\mathrm{H}]+418.21$ found $418.31[\mathrm{M}+\mathrm{H}]+.{ }^{1} \mathrm{H}$ NMR $\left(500 \mathrm{MHz}, \mathrm{CDCl}_{3}\right) \delta \mathrm{ppm} 8.19(\mathrm{~d}, J=2.0 \mathrm{~Hz}, 1 \mathrm{H}) 7.61(\mathrm{dd}$, $J=8.4,2.3 \mathrm{~Hz}, 1 \mathrm{H}) 7.20(\mathrm{~d}, J=8.4 \mathrm{~Hz}, 2 \mathrm{H}) 6.96(\mathrm{~d}, J=6.1 \mathrm{~Hz}, 1 \mathrm{H}) 6.73-6.79(\mathrm{~m}, 3 \mathrm{H}) 6.52(\mathrm{~d}$, $J=5.8 \mathrm{~Hz}, 1 \mathrm{H}) 4.32(\mathrm{br} \mathrm{s}, 2 \mathrm{H}) 4.22(\mathrm{br} \mathrm{s}, 1 \mathrm{H}) 3.90-3.99(\mathrm{~m}, 5 \mathrm{H}) 2.39(\mathrm{~s}, 3 \mathrm{H}) 1.68-1.78(\mathrm{~m}, 2$ H) $1.38(\mathrm{dq}, J=15.2,7.4 \mathrm{~Hz}, 2 \mathrm{H}) 0.94(\mathrm{t}, J=7.4 \mathrm{~Hz}, 3 \mathrm{H})$.

\section{Synthesis of 7-butyl-3-[3-chloro-4-(cyclopropylmethoxy)phenyl]-2-methyl-imidazo[1,2-} a]pyrazin-8-one (3e).

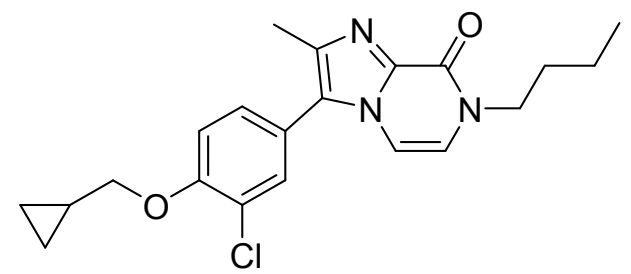

This reaction was carried out according to the procedure described for $\mathbf{3 b}$ using the following: Tetrakis(triphenylphosphine)palladium $(0.061 \mathrm{~g}, 0.0528 \mathrm{mmol}), 7(0.15 \mathrm{~g}, 0.528 \mathrm{mmol}), 2-[3-$ chloro-4-(cyclopropylmethoxy)phenyl]-4,4,5,5-tetramethyl-1,3,2-dioxaborolane (0.196 g, 0.633 mmol; C.A.S. $1860005-05-5)$ in a mixture of $\mathrm{NaHCO}_{3}(1.5 \mathrm{~mL})$ and dioxane $(3 \mathrm{~mL})$. This reaction yielded 3e $(0.105$ g, $52 \%)$ as white solid. $\mathrm{C}_{21} \mathrm{H}_{24} \mathrm{ClN}_{3} \mathrm{O}_{2}$ LC-MS m/z: calculated for $[\mathrm{M}+\mathrm{H}]+$ 386.15 found $386.25[\mathrm{M}+\mathrm{H}]+.{ }^{1} \mathrm{H}$ NMR $\left(400 \mathrm{MHz}, \mathrm{CDCl}_{3}\right) \delta \mathrm{ppm} 7.41(\mathrm{~d}, J=2.3 \mathrm{~Hz}, 1 \mathrm{H}) 7.23$ (dd, $J=8.3,2.1 \mathrm{~Hz}, 1 \mathrm{H}) 7.04(\mathrm{~d}, J=8.6 \mathrm{~Hz}, 1 \mathrm{H}) 6.92(\mathrm{~d}, J=5.8 \mathrm{~Hz}, 1 \mathrm{H}) 6.57(\mathrm{~d}, J=5.8 \mathrm{~Hz}, 1 \mathrm{H})$ 
$3.91-4.00(\mathrm{~m}, 4 \mathrm{H}) 2.39(\mathrm{~s}, 3 \mathrm{H}) 1.68-1.79(\mathrm{~m}, 2 \mathrm{H}) 1.31-1.44(\mathrm{~m}, 3 \mathrm{H}) 0.95(\mathrm{t}, J=7.4 \mathrm{~Hz}, 3 \mathrm{H})$ $0.63-0.76(\mathrm{~m}, 2 \mathrm{H}) 0.37-0.49$ (m, $2 \mathrm{H})$.

Synthesis of 7-butyl-3-[3-chloro-4-(tetrahydropyran-4-ylamino)phenyl]-2-methylimidazo[1,2-a]pyrazin-8-one (3h).

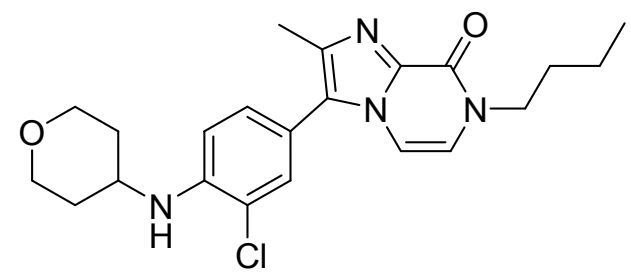

This reaction was carried out according to the procedure described for $\mathbf{3 b}$ using the following: Tetrakis(triphenylphosphine)palladium $(0.813 \mathrm{~g}, 0.0704 \mathrm{mmol}), 7(0.2 \mathrm{~g}, 0.704 \mathrm{mmol})$, commercial N-[2-chloro-4-(4,4,5,5-tetramethyl-1,3,2-dioxaborolan-2-yl)phenyl]tetrahydropyran4-amine $(0.285 \mathrm{~g}, 0.845 \mathrm{mmol}$; C.A.S. $1056465-07-6)$ in a mixture of $\mathrm{NaHCO}_{3}(1.5 \mathrm{~mL})$ and dioxane $(3 \mathrm{~mL})$. This reaction yielded $3 \mathbf{h}(0.195 \mathrm{~g}, 66.8 \%)$ as white solid. LC-MS m/z: calculated for $\mathrm{C}_{22} \mathrm{H}_{27} \mathrm{ClN}_{4} \mathrm{O}_{2}[\mathrm{M}+\mathrm{H}]+415.18$ found $415.2[\mathrm{M}+\mathrm{H}]+.{ }^{1} \mathrm{H}$ NMR $\left(400 \mathrm{MHz}, \mathrm{CDCl}_{3}\right) \delta \mathrm{ppm}$ $7.30(\mathrm{~d}, J=1.8 \mathrm{~Hz}, 1 \mathrm{H}) 7.15(\mathrm{dd}, J=8.4,2.0 \mathrm{~Hz}, 1 \mathrm{H}) 6.94(\mathrm{~d}, J=5.8 \mathrm{~Hz}, 1 \mathrm{H}) 6.80(\mathrm{~d}, J=8.6 \mathrm{~Hz}, 1$ H) $6.56(\mathrm{~d}, J=6.0 \mathrm{~Hz}, 1 \mathrm{H}) 4.47(\mathrm{br} \mathrm{d}, J=7.6 \mathrm{~Hz}, 1 \mathrm{H}) 4.05(\mathrm{dt}, J=11.8,3.7 \mathrm{~Hz}, 2 \mathrm{H}) 3.95(\mathrm{t}, J=7.4$ Hz, 2 H) 3.55 - 3.68 (m, 1 H) 3.57 (td, $J=11.4,2.3$ Hz, 2 H) 2.39 (s, 3 H) 2.04 - 2.14 (m, 2 H) 1.68 - 1.79 (m, 2 H) 1.54 - 1.67 (m, 2 H) 1.39 (dq, $J=15.1,7.5 \mathrm{~Hz}, 2 \mathrm{H}) 0.95$ (t, $J=7.4 \mathrm{~Hz}, 3 \mathrm{H})$.

Synthesis of 7-butyl-3-(3-chloro-4-piperazin-1-yl-phenyl)-2-methyl-imidazo[1,2-a]pyrazin8-one (3g). 


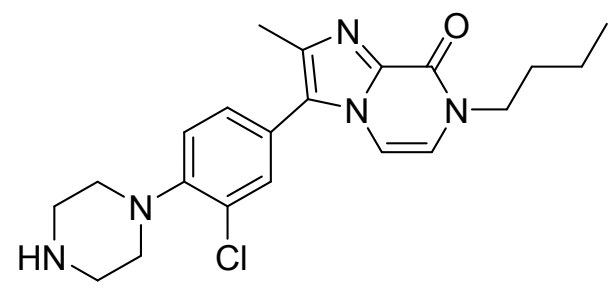

This reaction was carried out according to the procedure described for $\mathbf{3 b}$ using the following: Tetrakis(triphenylphosphine)palladium $(0.06 \mathrm{~g}, 0.0513 \mathrm{mmol}), 7(0.583 \mathrm{~g}, 2.052 \mathrm{mmol})$, tertbutyl-4-[2-chloro-4-(4,4,5,5-tetramethyl-1,3,2-dioxaborolan-2-yl)phenyl]piperazine-1carboxylate $(1.24 \mathrm{~g}, 2.257 \mathrm{mmol})$ in a mixture of $\mathrm{NaHCO}_{3}(6 \mathrm{~mL})$ and dioxane $(14 \mathrm{~mL})$. This reaction yielded tert-butyl 4-[4-(7-butyl-2-methyl-8-oxo-imidazo[1,2-a]pyrazin-3-yl)-2-chlorophenyl]piperazine-1-carboxylate $(0.677 \mathrm{~g}, 66 \%)$. TFA (2.54 $\mathrm{mL}, 33.237 \mathrm{mmol}, 1.49 \mathrm{~g} / \mathrm{mL})$ was added to a solution of tert-butyl 4-[4-(7-butyl-2-methyl-8-oxo-imidazo[1,2-a]pyrazin-3-yl)-2chloro-phenyl]piperazine-1-carboxylate $(0.277 \mathrm{~g}, 0.554 \mathrm{mmol})$, in DCM $(18 \mathrm{~mL})$ at $\mathrm{rt}$. The mixture was stirred at $\mathrm{rt}$ for $2 \mathrm{~h}$. The solvent was evaporated in vacuo and the crude was diluted with saturated solution of $\mathrm{NaHCO}_{3}$ and extracted with DCM. The organic layer was separated, washed with brine, separated, dried $\left(\mathrm{Na}_{2} \mathrm{SO}_{4}\right)$, filtered, concentrated in vacuo and triturated with $\mathrm{Et}_{2} \mathrm{O}$, filtered to yield $\mathbf{3 g}(0.147 \mathrm{~g}, 63.3 \%)$ as a pale yellow solid. LC-MS m/z: calculated for $\mathrm{C}_{21} \mathrm{H}_{26} \mathrm{ClN}_{5} \mathrm{O}[\mathrm{M}+\mathrm{H}]+400.18$ found $400.22[\mathrm{M}+\mathrm{H}]+.{ }^{1} \mathrm{H}$ NMR $\left(400 \mathrm{MHz}, \mathrm{CDCl}_{3}\right) \delta \mathrm{ppm} 7.40$ $(\mathrm{d}, J=2.1 \mathrm{~Hz}, 1 \mathrm{H}) 7.24-7.29(\mathrm{~m}, 1 \mathrm{H}) 7.16(\mathrm{~d}, J=8.3 \mathrm{~Hz}, 1 \mathrm{H}) 6.96(\mathrm{~d}, J=6.0 \mathrm{~Hz}, 1 \mathrm{H}) 6.58(\mathrm{~d}$, $J=5.8 \mathrm{~Hz}, 1 \mathrm{H}) 3.96(\mathrm{t}, J=7.4 \mathrm{~Hz}, 2 \mathrm{H}) 3.06-3.20(\mathrm{~m}, 8 \mathrm{H}) 2.41(\mathrm{~s}, 3 \mathrm{H}) 1.66-1.83(\mathrm{~m}, 3 \mathrm{H}) 1.39$ (dq, $J=15.1,7.5 \mathrm{~Hz}, 2 \mathrm{H}) 0.95(\mathrm{t}, J=7.4 \mathrm{~Hz}, 3 \mathrm{H})$.

Synthesis of 7-butyl-3-(1H-indol-5-yl)-2-methyl-imidazo[1,2-a]pyrazin-8-one (3h). 


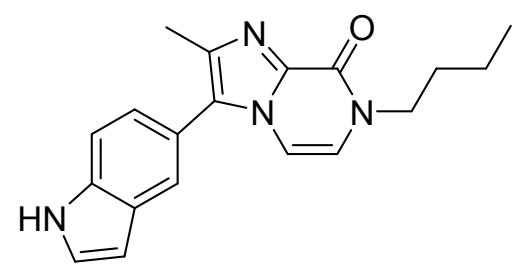

This reaction was carried out according to the procedure described for $\mathbf{3 b}$ using the following: Tetrakis(triphenylphosphine)palladium $(0.06 \mathrm{~g}, 0.0528 \mathrm{mmol}), 7(0.150 \mathrm{~g}, 0.528 \mathrm{mmol}), 6-$ (4,4,5,5-tetramethyl-1,3,2-dioxaborolan-2-yl)-1H-indole ( 0.154 g, 0.63 mmol; C.A.S. 269410-244) in a mixture of $\mathrm{NaHCO}_{3}(1.5 \mathrm{~mL})$ and dioxane $(3 \mathrm{~mL})$. This reaction yielded $\mathbf{3 h}(0.105 \mathrm{~g}, 62$ \%) as white solid. LC-MS m/z: calculated for $\mathrm{C}_{19} \mathrm{H}_{20} \mathrm{~N}_{4} \mathrm{O}[\mathrm{M}+\mathrm{H}]+321.16$ found $321.26[\mathrm{M}+\mathrm{H}]+$. ${ }^{1} \mathrm{H}$ NMR $\left(400 \mathrm{MHz}, \mathrm{CDCl}_{3}\right) \delta$ ppm 8.46 (br s, $\left.1 \mathrm{H}\right) 7.66-7.69$ (m, $\left.1 \mathrm{H}\right) 7.55$ (br d, $J=8.3 \mathrm{~Hz}, 1$ H) $7.32-7.35(\mathrm{~m}, 1 \mathrm{H}) 7.20(\mathrm{dd}, J=8.4,1.5 \mathrm{~Hz}, 1 \mathrm{H}) 7.02(\mathrm{~d}, J=6.0 \mathrm{~Hz}, 1 \mathrm{H}) 6.64$ (ddd, $J=3.2,2.1$, $0.9 \mathrm{~Hz}, 1 \mathrm{H}) 6.53(\mathrm{~d}, J=5.8 \mathrm{~Hz}, 1 \mathrm{H}) 3.96(\mathrm{t}, J=7.4 \mathrm{~Hz}, 2 \mathrm{H}) 2.44(\mathrm{~s}, 3 \mathrm{H}) 1.68-1.79(\mathrm{~m}, 2 \mathrm{H}) 1.40$ (dq, $J=15.1,7.5 \mathrm{~Hz}, 2 \mathrm{H}) 0.95$ (t, $J=7.3 \mathrm{~Hz}, 3 \mathrm{H})$.

\section{Synthesis of 7-butyl-2-methyl-3-[1-(3-pyridyl)indol-5-yl]imidazo[1,2-a]pyrazin-8-one (3i).}

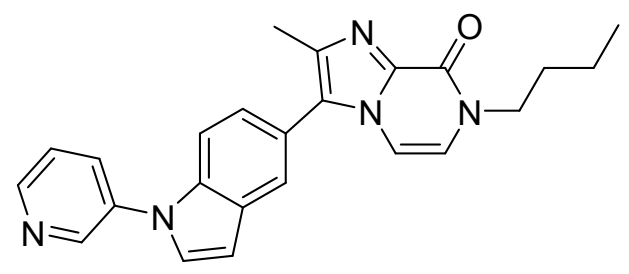

This reaction was carried out according to the procedure described for $\mathbf{3 b}$ using the following: Tetrakis(triphenylphosphine)palladium $(0.081 \mathrm{~g}, 0.07 \mathrm{mmol}), 7(0.2 \mathrm{~g}, 0.704 \mathrm{mmol}), 1-(3-$ pyridinyl)-5-(,4,5,5-tetramethyl-1,3,2-dioxaborolan-2-yl)-1H-indole $\quad(0.270 \quad \mathrm{~g}, \quad 0.845 \mathrm{mmol}$; C.A.S. 1065270-19-0) in a mixture of $\mathrm{NaHCO}_{3}(1.5 \mathrm{~mL})$ and dioxane $(3 \mathrm{~mL})$. This reaction yielded 3i (0.085 g, $30 \%$ ) as white solid. LC-MS m/z: calculated for $\mathrm{C}_{24} \mathrm{H}_{23} \mathrm{~N}_{5} \mathrm{O}[\mathrm{M}+\mathrm{H}]+398.1$ 
found $398.2[\mathrm{M}+\mathrm{H}]+.{ }^{1} \mathrm{H}$ NMR $\left(400 \mathrm{MHz}, \mathrm{CDCl}_{3}\right) \delta \mathrm{ppm} 8.88(\mathrm{br} \mathrm{d}, J=2.1 \mathrm{~Hz}, 1 \mathrm{H}) 8.68(\mathrm{dd}$, $J=4.7,1.5 \mathrm{~Hz}, 1 \mathrm{H}) 7.88(\mathrm{ddd}, J=8.1,2.6,1.5 \mathrm{~Hz}, 1 \mathrm{H}) 7.73(\mathrm{~d}, J=1.2 \mathrm{~Hz}, 1 \mathrm{H}) 7.64(\mathrm{br} \mathrm{d}, J=8.6$ $\mathrm{Hz}, 1 \mathrm{H}) 7.53$ (ddd, $J=8.1,4.9,0.8 \mathrm{~Hz}, 1 \mathrm{H}) 7.43$ (d, $J=3.5 \mathrm{~Hz}, 1 \mathrm{H}) 7.26($ br dd, $J=8.6,1.6 \mathrm{~Hz}, 1$ H) $7.02(\mathrm{~d}, J=5.8 \mathrm{~Hz}, 1 \mathrm{H}) 6.82(\mathrm{dd}, J=3.2,0.7 \mathrm{~Hz}, 1 \mathrm{H}) 6.56(\mathrm{~d}, J=6.0 \mathrm{~Hz}, 1 \mathrm{H}) 3.97(\mathrm{t}, J=7.4 \mathrm{~Hz}$, 2 H) 2.45 (s, 3 H) $1.70-1.80$ (m, 2 H) 1.40 (dq, $J=15.1,7.5 \mathrm{~Hz}, 2$ H) 0.95 (t, $J=7.4 \mathrm{~Hz}, 3 \mathrm{H})$.

\section{Synthesis of 7-butyl-2-methyl-3-(4-phenoxyphenyl)imidazo[1,2-a]pyrazin-8-one (3j).}

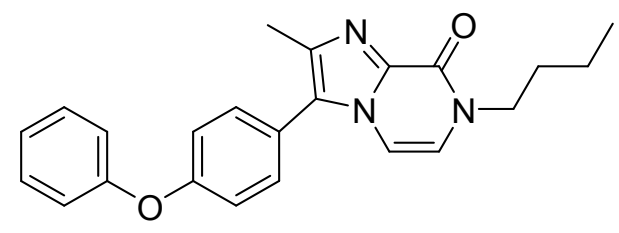

This reaction was carried out according to the procedure described for $\mathbf{3 b}$ using the following: Tetrakis(triphenylphosphine)palladium (0.049 g, $0.0423 \mathrm{mmol}), 7$ (0.120 g, $0.423 \mathrm{mmol}), 4,4,5,5-$ tetramethyl-2-(4-phenoxyphenyl)-1,3,2-dioxaborolane (0.1 g, 0.465 mmol; C.A.S. 269410-26-6) in a mixture of $\mathrm{NaHCO}_{3}(1.5 \mathrm{~mL})$ and dioxane $(3 \mathrm{~mL})$. This reaction yielded $\mathbf{3} \mathbf{j}(0.149 \mathrm{~g}, 88 \%)$ as white solid. LC-MS m/z: calculated for $\mathrm{C}_{23} \mathrm{H}_{23} \mathrm{~N}_{3} \mathrm{O}_{2}[\mathrm{M}+\mathrm{H}]+374.17$ found $374.21[\mathrm{M}+\mathrm{H}]+.{ }^{1} \mathrm{H}$ NMR (500 MHz, $\left.\mathrm{CDCl}_{3}\right) \delta$ ppm 7.38 - $7.43(\mathrm{~m}, 2 \mathrm{H}) 7.33$ - 7.37 (m, 2 H) 7.16 - 7.21 (m, $\left.1 \mathrm{H}\right) 7.08$ - $7.15(\mathrm{~m}, 4 \mathrm{H}) 6.98(\mathrm{~d}, J=5.8 \mathrm{~Hz}, 1 \mathrm{H}) 6.56(\mathrm{~d}, J=5.8 \mathrm{~Hz}, 1 \mathrm{H}) 3.96(\mathrm{t}, J=7.4 \mathrm{~Hz}, 2 \mathrm{H}) 2.42(\mathrm{~s}, 3$ H) 1.69 - 1.78 (m, 2 H) 1.39 (dq, J=15.0, $7.5 \mathrm{~Hz}, 2 \mathrm{H}) 0.95$ (t, J=7.4 Hz, $3 \mathrm{H})$.

\section{Synthesis of 7-butyl-2-methyl-8-oxo-imidazo[1,2-a]pyrazine-3-carbaldehyde (9).}



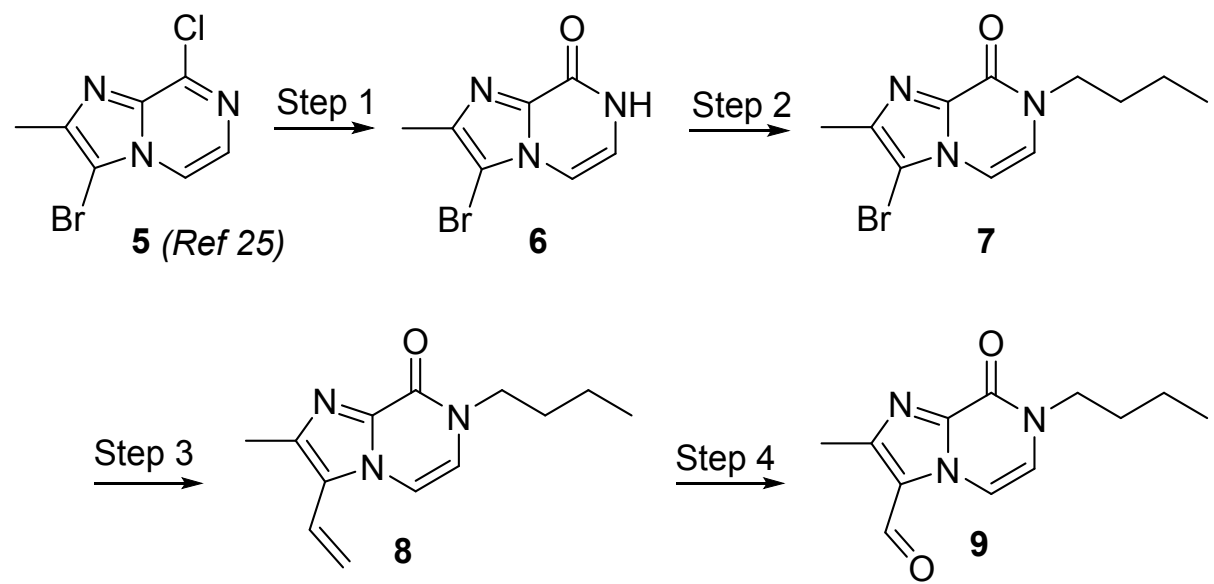

Step 1: A mixture of $5(1.15 \mathrm{~g}, 4.66 \mathrm{mmol})$ in $\mathrm{HCl}\left(37 \%\right.$ in $\left.\mathrm{H}_{2} \mathrm{O}\right)(5.84 \mathrm{~mL}, 70 \mathrm{mmol}, 1.16 \mathrm{~g} / \mathrm{mL})$ was stirred at $95{ }^{\circ} \mathrm{C}$ for $2 \mathrm{~h}$. The mixture was concentrated in vacuo and triturated with $\mathrm{Et}_{2} \mathrm{O}$, filtered to yield intermediate $6(1 \mathrm{~g}, 81 \%)$ as pale brown solid. LC-MS m/z: calculated for $\mathrm{C}_{7} \mathrm{H}_{6} \mathrm{BrN}_{3} \mathrm{O}[\mathrm{M}+\mathrm{H}]+227.96$ found $228.10[\mathrm{M}+\mathrm{H}]+.{ }^{1} \mathrm{H}$ NMR $\left(400 \mathrm{MHz}\right.$, DMSO- $\left.d_{6}\right) \delta \mathrm{ppm}$ $11.67($ br s, $1 \mathrm{H}) 7.30(\mathrm{~d}, J=5.8 \mathrm{~Hz}, 1 \mathrm{H}) 7.05(\mathrm{t}, J=5.3 \mathrm{~Hz}, 1 \mathrm{H}) 2.30(\mathrm{~s}, 3 \mathrm{H})$.

Step 2: 1-Bromobutane ( $0.6 \mathrm{~mL}, 5.52 \mathrm{mmol}, 1.27 \mathrm{~g} / \mathrm{mL})$ was added to a solution of $6(1.2 \mathrm{~g}, 5.26$ $\mathrm{mmol}), \mathrm{Cs}_{2} \mathrm{CO}_{3}(3.63 \mathrm{~g}, 11.05 \mathrm{mmol})$ in 1,4-dioxane $(12 \mathrm{~mL})$ at $\mathrm{rt}$. The mixture was stirred at 90 ${ }^{\circ} \mathrm{C} \mathrm{rt}$ for $48 \mathrm{~h}$. The mixture was filtered through celite, concentrated in vacuo and triturated with $\mathrm{Et}_{2} \mathrm{O}$, filtered to yield intermediate $7(1.47 \mathrm{~g}, 98 \%)$ as solid. LC-MS m/z: calculated for C11H14BrN3O $[\mathrm{M}+\mathrm{H}]+284.1$ found $284.2[\mathrm{M}+\mathrm{H}]+{ }^{1} \mathrm{H}$ NMR $\left(400 \mathrm{MHz}, \mathrm{CDCl}_{3}\right) \delta \mathrm{ppm} 7.04$ (d, $J=5.8 \mathrm{~Hz}, 1 \mathrm{H}) 6.70(\mathrm{~d}, J=6.0 \mathrm{~Hz}, 1 \mathrm{H}) 3.96(\mathrm{t}, J=7.4 \mathrm{~Hz}, 2 \mathrm{H}) 2.39(\mathrm{~s}, 3 \mathrm{H}) 1.67-1.79(\mathrm{~m}, 2$ H) $1.38(\mathrm{dq}, J=15.1,7.4 \mathrm{~Hz}, 2 \mathrm{H}) 0.95(\mathrm{t}, J=7.3 \mathrm{~Hz}, 3 \mathrm{H})$.

Step 3: Tetrakis(triphenylphosphine)palladium $(0.36 \mathrm{~g}, 0.317 \mathrm{mmol})$ was added to a deoxygenated and stirred suspension of $7(1 \mathrm{~g}, 3.52 \mathrm{mmol})$, vinylboronic acid pinacol ester ( $1.07 \mathrm{~mL}, 6.33 \mathrm{mmol}$, $0.908 \mathrm{~g} / \mathrm{mL})$ in a mixture of $\mathrm{NaHCO}_{3}(3 \mathrm{~mL})$ and dioxane $(6 \mathrm{~mL})$ at $\mathrm{rt}$ under Nitroben. The mixture was heated under $\mathrm{MW}$ irradiation at $150{ }^{\circ} \mathrm{C}$ for $10 \mathrm{~min}$. The crude was diluted with saturated solution of $\mathrm{NaHCO}_{3}$ and extracted with DCM. The organic layer was separated, washed with brine, 
separated, dried $\left(\mathrm{Na}_{2} \mathrm{SO}_{4}\right)$, filtered and concentrated in vacuo. The residue thus obtained was purified by flash chromatography (silica, MeOH/DCM from 0/100 to 9/91). The desired fractions were collected and concentrated in vacuo to yield intermediate $\mathbf{8}(0.81 \mathrm{~g}, 59 \%)$ as a pale brown solid. LC-MS m/z: calculated for $\mathrm{C}_{13} \mathrm{H}_{17} \mathrm{~N}_{3} \mathrm{O}[\mathrm{M}+\mathrm{H}]+232.1$ found $232.12[\mathrm{M}+\mathrm{H}]+.{ }^{1} \mathrm{H}$ NMR $\left(400 \mathrm{MHz}, \mathrm{CDCl}_{3}\right) \delta$ ppm $7.07(\mathrm{~d}, J=5.8 \mathrm{~Hz}, 1 \mathrm{H}) 6.66(\mathrm{dd}, J=17.8,11.8 \mathrm{~Hz}, 1 \mathrm{H}) 6.63(\mathrm{~d}, J=6.0$ Hz, 1 H) 5.63 (d, $J=17.8 \mathrm{~Hz}, 1 \mathrm{H}) 5.54$ (d, $J=11.8 \mathrm{~Hz}, 1 \mathrm{H}) 3.95$ (t, $J=7.4 \mathrm{~Hz}, 2 \mathrm{H}) 2.49$ (s, $3 \mathrm{H})$ $1.68-1.78(\mathrm{~m}, 2 \mathrm{H}) 1.38(\mathrm{dq}, J=15.1,7.4 \mathrm{~Hz}, 2 \mathrm{H}) 0.94(\mathrm{t}, J=7.4 \mathrm{~Hz}, 3 \mathrm{H})$.

Step 4: $\mathrm{OsO}_{4}\left(2.5 \%\right.$ in $\left.{ }^{\mathrm{t}} \mathrm{BuOH}\right)(0.76 \mathrm{~mL}, 0.059 \mathrm{mmol}, 0.81 \mathrm{~g} / \mathrm{mL})$, was added to a solution of 8 (0.62 $\mathrm{g}, 1.47 \mathrm{mmol}), \mathrm{NaIO}_{4}(0.94 \mathrm{~g}, 4.34 \mathrm{mmol})$ in a mixture of dioxane $(15 \mathrm{~mL})$ and water $(3$ $\mathrm{mL}$ ) at $\mathrm{rt}$. The mixture was stirred at $\mathrm{rt}$ for $2 \mathrm{~h}$. The crude was diluted with water and extracted with AcOEt. The organic layer was separated, washed with brine, separated, dried $\left(\mathrm{Na}_{2} \mathrm{SO}_{4}\right)$, filtered and concentrated in vacuo to yield intermediate $9(0.56 \mathrm{~g}, 65 \%)$ as oil. LC-MS m/z: calculated for $\mathrm{C}_{12} \mathrm{H}_{15} \mathrm{~N}_{3} \mathrm{O}_{2}[\mathrm{M}+\mathrm{H}]+234.1$ found $234.2[\mathrm{M}+\mathrm{H}]+$.

\section{Synthesis of 4a-d (core variations):}

Synthesis of 7-butyl-3-[3-chloro-4-(cyclopropylmethoxy)phenyl]-[1,2,4]triazolo[4,3a]pyrazin-8-one (4a).

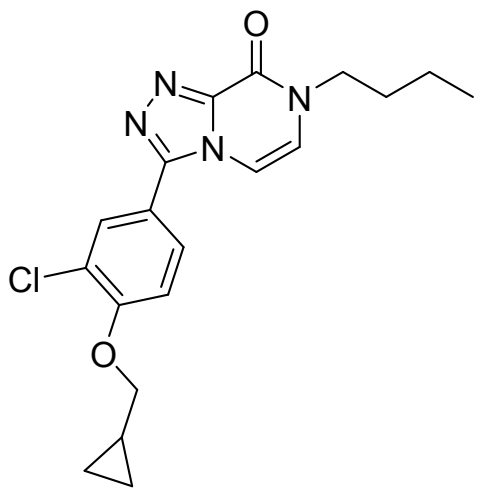


Tetrakis(triphenylphosphine)palladium (0) $(0.021 \mathrm{~g}, 0.0177 \mathrm{mmol})$ was added to a deoxygenated and stirred suspension of 16 (0.080 g, $0.353 \mathrm{mmol})$, 2-[3-chloro-4-(cyclopropylmethoxy)-phenyl]4,4,5,5-tetramethyl-1,3,2-dioxaborolane (0.131g, $0.424 \mathrm{mmol}$; C.A.S. 1860005-05-5) in a mixture of saturated solution of $\mathrm{NaHCO}_{3}(1.5 \mathrm{~mL})$ and dioxane $(3 \mathrm{~mL})$ at $\mathrm{rt}$ under Nitrogen. The mixture was heated under MW irradiation at $150{ }^{\circ} \mathrm{C}$ for $10 \mathrm{~min}$. The crude was cooled and diluted with water and extracted with DCM. The organic layer was separated, washed with brine, separated, dried $\left(\mathrm{Na}_{2} \mathrm{SO}_{4}\right)$, filtered and concentrated in vacuo. The residue thus obtained was purified by flash chromatography (silica, $\mathrm{MeOH}-\mathrm{NH}_{3} / \mathrm{DCM}$ from 0/100 to 4/96). The desired fractions were collected and concentrated in vacuo to yield $4 \mathbf{a}(0.109 \mathrm{~g}, 83 \%)$ as a pale brown solid. LC-MS m/z: calculated for $\mathrm{C}_{19} \mathrm{H}_{21} \mathrm{ClN}_{4} \mathrm{O}_{2}[\mathrm{M}+\mathrm{H}]+373.13$ found $373.23[\mathrm{M}+\mathrm{H}]+.{ }^{1} \mathrm{H} \mathrm{NMR}\left(400 \mathrm{MHz}, \mathrm{CDCl}_{3}\right)$ $\delta$ ppm $7.80(\mathrm{~d}, J=2.1 \mathrm{~Hz}, 1 \mathrm{H}) 7.68(\mathrm{dd}, J=8.4,2.2 \mathrm{~Hz}, 1 \mathrm{H}) 7.18(\mathrm{~d}, J=6.0 \mathrm{~Hz}, 1 \mathrm{H}) 7.07$ (d, $J=8.6$ Hz, 1 H) $6.68(\mathrm{~d}, J=6.0 \mathrm{~Hz}, 1 \mathrm{H}) 3.95-4.02(\mathrm{~m}, 4 \mathrm{H}) 1.71-1.81(\mathrm{~m}, 2 \mathrm{H}) 1.31-1.47(\mathrm{~m}, 3 \mathrm{H})$ $0.98(\mathrm{t}, J=7.4 \mathrm{~Hz}, 3 \mathrm{H}) 0.65-0.75(\mathrm{~m}, 2 \mathrm{H}) 0.37-0.50(\mathrm{~m}, 2 \mathrm{H})$.

\section{Synthesis of 3-butyl-7-[3-chloro-4-(cyclopropylmethoxy)phenyl]imidazo[2,1-f][1,2,4]triazin-}

\section{4-one (4b).}

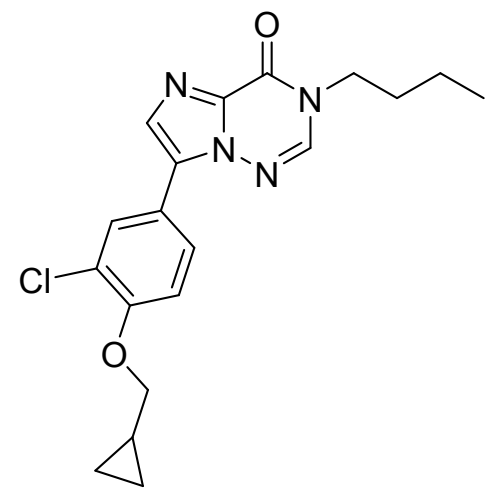


Palladium(II) acetate $(0.0035 \mathrm{~g}, 0.01556 \mathrm{mmol})$ was added to a deoxygenated and stirred suspension of 19 ( $0.23 \mathrm{~g}, 0.778 \mathrm{mmol}$ ), 4-bromo-2-chloro-1-(cyclopropylmethoxy)-benzene (0.262 g, 0.933mmol; C.A.S. $1369869-79-3), \mathrm{PPh}_{3}(0.008156$ g, $0.0311 \mathrm{mmol})$, AcOK (0.153 g, $1.55 \mathrm{mmol})$, in DMA (3 mL) at rt under Nitrogen. The mixture was heated at $120^{\circ} \mathrm{C}$ for $30 \mathrm{~h}$. The crude was cooled and diluted with Ethyl Acetate and washed with brine. The organic layer was separated, dried $\left(\mathrm{Na}_{2} \mathrm{SO}_{4}\right)$, filtered and concentrated in vacuo. The residue thus obtained was purified by flash chromatography (silica, AcOEt/DCM from 0/100 to 20/80). The desired fractions were collected and concentrated in vacuo to yield $\mathbf{4 b}(0.1 \mathrm{~g}, 35 \%)$ as white solid. LC-MS m/z: calculated for $\mathrm{C}_{19} \mathrm{H}_{21} \mathrm{ClN}_{4} \mathrm{O}_{2}[\mathrm{M}+\mathrm{H}]+373.1$ found $[\mathrm{M}+\mathrm{H}]+373.21 .{ }^{1} \mathrm{H} \mathrm{NMR}\left(400 \mathrm{MHz}, \mathrm{CDCl}_{3}\right)$ $\delta$ ppm $7.98(\mathrm{~d}, J=2.1 \mathrm{~Hz}, 1 \mathrm{H}) 7.75(\mathrm{~s}, 1 \mathrm{H}) 7.70(\mathrm{~s}, 1 \mathrm{H}) 7.70(\mathrm{dd}, J=8.6,2.1 \mathrm{~Hz}, 1 \mathrm{H}) 7.00(\mathrm{~d}$, $J=8.6 \mathrm{~Hz}, 1 \mathrm{H}) 4.01(\mathrm{t}, J=7.3 \mathrm{~Hz}, 2 \mathrm{H}) 3.95(\mathrm{~d}, J=6.7 \mathrm{~Hz}, 2 \mathrm{H}) 1.73-1.84(\mathrm{~m}, 2 \mathrm{H}) 1.29-1.48(\mathrm{~m}$, $3 \mathrm{H}) 0.98(\mathrm{t}, J=7.4 \mathrm{~Hz}, 3 \mathrm{H}) 0.61-0.75(\mathrm{~m}, 2 \mathrm{H}) 0.35-0.48(\mathrm{~m}, 2 \mathrm{H}) .{ }^{13} \mathrm{C} \mathrm{NMR}\left(101 \mathrm{MHz}, \mathrm{CDCl}_{3}\right)$ $\delta$ ppm 154.91 (s, 1 C) 151.77 (s, 1 C) 141.13 (s, 1 C) 133.63 (s, 1 C) 130.35 (s, 1 C) 129.87 (s, 1 C) $129.33(\mathrm{~s}, 1 \mathrm{C}) 127.00(\mathrm{~s}, 1 \mathrm{C}) 123.52(\mathrm{~s}, 1 \mathrm{C}) 120.76(\mathrm{~s}, 1 \mathrm{C}) 113.74(\mathrm{~s}, 1 \mathrm{C}) 73.92(\mathrm{~s}, 1 \mathrm{C})$ 46.30 (s, 1 C) 31.36 (s, 1 C) 19.76 (s, 1 C) 13.58 (s, 1 C) 10.09 (s, 1 C) 3.27 (s, 2 C).

Synthesis of 7-butyl-3-[3-chloro-4-(cyclopropylmethoxy)phenyl]imidazo[1,2d][1,2,4] triazin-8-one (4c).

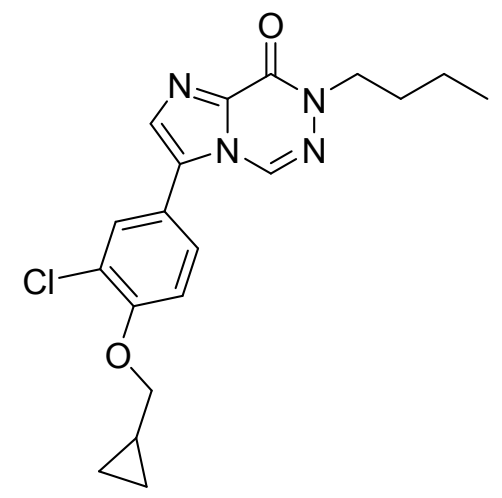


Palladium(II) acetate $(0.0033 \mathrm{~g}, 0.0146 \mathrm{mmol})$ was added to a deoxygenated and stirred suspension of 21 ( $0.140 \mathrm{~g}, 0.728 \mathrm{mmol})$, 4-bromo-2-chloro-1-(cyclopropylmethoxy)-benzene ( $0.228 \mathrm{~g}, 0.874$ mmol; C.A.S. 1369869-79-3), $\mathrm{PPh}_{3}(0.0076 \mathrm{~g}, 0.0291 \mathrm{mmol})$, AcOK (0.107 g, $\left.1.092 \mathrm{mmol}\right)$, in DMA $(3 \mathrm{~mL})$ at $\mathrm{rt}$ under Nitrogen. The mixture was heated at $120{ }^{\circ} \mathrm{C}$ for $30 \mathrm{~h}$. The crude was cooled and diluted with Ethyl Acetate and washed with brine. The organic layer was separated, dried $\left(\mathrm{Na}_{2} \mathrm{SO}_{4}\right)$, filtered and concentrated in vacuo. The residue thus obtained was purified by flash chromatography (silica, AcOEt/DCM from 0/100 to 20/80). The desired fractions were collected and concentrated in vacuo to yield $4 \mathbf{c}(0.15 \mathrm{~g}, 55 \%)$ as white solid. LC-MS m/z: calculated for $\mathrm{C}_{19} \mathrm{H}_{21} \mathrm{ClN}_{4} \mathrm{O}_{2}[\mathrm{M}+\mathrm{H}]+373.1$ found $[\mathrm{M}+\mathrm{H}]+373.21 .{ }^{1} \mathrm{H} \mathrm{NMR}\left(400 \mathrm{MHz}, \mathrm{CDCl}_{3}\right) \delta \mathrm{ppm} 8.19(\mathrm{~s}$,

$1 \mathrm{H}) 7.58(\mathrm{~s}, 1 \mathrm{H}) 7.53(\mathrm{~d}, J=2.3 \mathrm{~Hz}, 1 \mathrm{H}) 7.34(\mathrm{dd}, J=8.3,2.3 \mathrm{~Hz}, 1 \mathrm{H}) 7.05(\mathrm{~d}, J=8.6 \mathrm{~Hz}, 1 \mathrm{H})$ $4.16(\mathrm{t}, J=7.3 \mathrm{~Hz}, 2 \mathrm{H}) 3.97(\mathrm{~d}, J=6.9 \mathrm{~Hz}, 2 \mathrm{H}) 1.75-1.85(\mathrm{~m}, 2 \mathrm{H}) 1.30-1.46(\mathrm{~m}, 3 \mathrm{H}) 0.96(\mathrm{t}$, $J=7.4 \mathrm{~Hz}, 3 \mathrm{H}) 0.62-0.78(\mathrm{~m}, 2 \mathrm{H}) 0.36-0.50(\mathrm{~m}, 2 \mathrm{H}) .{ }^{13} \mathrm{C} \mathrm{NMR}\left(101 \mathrm{MHz}, \mathrm{CDCl}_{3}\right) \delta \mathrm{ppm}$ $155.74(\mathrm{~s}, 1 \mathrm{C}) 152.26(\mathrm{~s}, 1 \mathrm{C}) 137.67(\mathrm{~s}, 1 \mathrm{C}) 132.66(\mathrm{~s}, 1 \mathrm{C}) 130.25(\mathrm{~s}, 1 \mathrm{C}) 128.00(\mathrm{~s}, 1 \mathrm{C})$ 127.46 (s, 1 C) 124.39 (s, 1 C) 119.56 (s, 1 C) $114.20(\mathrm{~s}, 1 \mathrm{C}) 74.02$ (s, 1 C) 49.63 (s, 1 C) 30.40 (s, 1 C) $19.80(\mathrm{~s}, 1 \mathrm{C}) 13.72$ (s, 1 C) 10.02 (s, 1 C) 3.31 (s, 2 C); 1H overlapped.

\section{Synthesis of 3-butyl-8-[3-chloro-4-(cyclopropylmethoxy)phenyl]-7-methyl-pyrazolo[1,5-} a][1,3,5]triazin-4-one (4d)

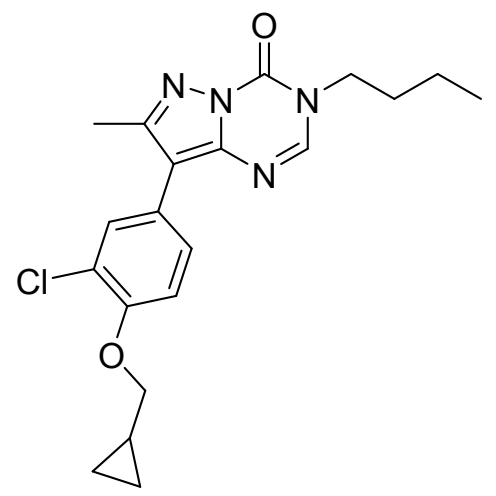


Tetrakis(triphenylphosphine)palladium $(0)(0.15 \mathrm{~g}, 0.526 \mathrm{mmol})$ was added to a deoxygenated and stirred suspension of 24 (0.150 g, 0.526mmol), 3-chloro-4-(cyclopropylmethoxy)-phenylboronic acid pinacol ester $(0.170 \mathrm{~g}, 0.552 \mathrm{mmol})$; C.A.S. $1860005-05-5)$ in a mixture of saturated solution of $\mathrm{NaHCO}_{3}(1.5 \mathrm{~mL})$ and dioxane $(3 \mathrm{~mL})$ at $\mathrm{rt}$ under Nitrogen. The mixture was heated under $\mathrm{MW}$ irradiation at $150{ }^{\circ} \mathrm{C}$ for $10 \mathrm{~min}$. The crude was cooled and diluted with water and extracted with DCM. The organic layer was separated, washed with brine, separated, dried $\left(\mathrm{Na}_{2} \mathrm{SO}_{4}\right)$, filtered and concentrated in vacuo. The residue thus obtained was purified by flash chromatography (silica, $\mathrm{MeOH}-\mathrm{NH}_{3} / \mathrm{DCM}$ from 0/100 to 4/96). The desired fractions were collected and concentrated in vacuo to yield $4 \mathbf{d}(0.180 \mathrm{~g}, 73 \%)$ as a white solid. LC-MS m/z: calculated for $\mathrm{C}_{20} \mathrm{H}_{23} \mathrm{ClN}_{4} \mathrm{O}_{2}$ $[\mathrm{M}+\mathrm{H}]+387.15$ found $387.21[\mathrm{M}+\mathrm{H}]+.{ }^{1} \mathrm{H} \mathrm{NMR}\left(400 \mathrm{MHz}, \mathrm{CDCl}_{3}\right) \delta \mathrm{ppm} 7.72(\mathrm{~s}, 1 \mathrm{H}) 7.62(\mathrm{~d}$, $J=2.3 \mathrm{~Hz}, 1 \mathrm{H}) 7.41(\mathrm{dd}, J=8.4,2.2 \mathrm{~Hz}, 1 \mathrm{H}) 7.00(\mathrm{~d}, J=8.6 \mathrm{~Hz}, 1 \mathrm{H}) 4.01(\mathrm{t}, J=7.3 \mathrm{~Hz}, 2 \mathrm{H}) 3.93$ (d, $J=6.7 \mathrm{~Hz}, 2 \mathrm{H}) 2.54(\mathrm{~s}, 3 \mathrm{H}) 1.74-1.85(\mathrm{~m}, 2 \mathrm{H}) 1.28-1.48(\mathrm{~m}, 3 \mathrm{H}) 0.98(\mathrm{t}, J=7.4 \mathrm{~Hz}, 3 \mathrm{H})$ $0.60-0.73(\mathrm{~m}, 2 \mathrm{H}) 0.34-0.47(\mathrm{~m}, 2 \mathrm{H})$.

Synthesis of 7-butyl-3-[3-chloro-4-(cyclopropylmethoxy)phenyl]-1-methyl-imidazo[1,5a]pyrazin-8-one (4e)

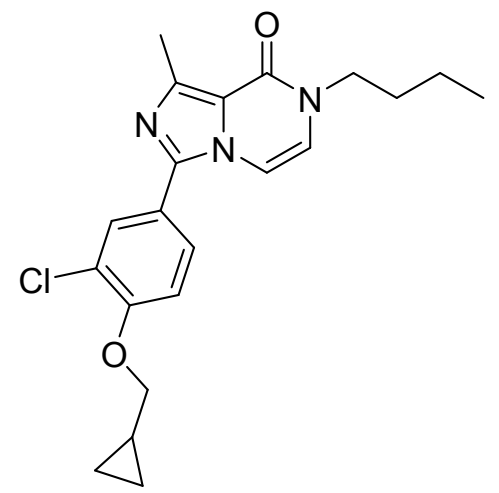

1-Bromobutane $(0.09 \mathrm{~mL}, 0.834 \mathrm{mmol}, 1.27 \mathrm{~g} / \mathrm{mL})$ was added to a solution of $28(0.25 \mathrm{~g}, 0.758$ $\mathrm{mmol})$ and $\mathrm{K}_{2} \mathrm{CO}_{3}(0.121 \mathrm{~g}, 1.137 \mathrm{mmol})$ in $\mathrm{MeCN}(3 \mathrm{~mL})$ at $\mathrm{rt}$. The mixture was heated under MW irradiation at $170{ }^{\circ} \mathrm{C}$ for $40 \mathrm{~min}$. The mixture was filtered through celite and concentrated in 
vacuo. The residue thus obtained was purified by flash chromatography (silica, $7 \mathrm{~N} \mathrm{NH}_{3}$ in $\mathrm{MeOH} / \mathrm{DCM}$ from 0/100 to 5/95). The desired fractions were collected and concentrated in vacuo to yield $4 \mathrm{e}(0.18 \mathrm{~g}, 62 \%)$ as white solid. $\mathrm{LC}-\mathrm{MS} \mathrm{m} / \mathrm{z}$ : calculated for $\mathrm{C}_{21} \mathrm{H}_{24} \mathrm{ClN}_{3} \mathrm{O}_{2}[\mathrm{M}+\mathrm{H}]+386.1$ found $386.2[\mathrm{M}+\mathrm{H}]+.{ }^{1} \mathrm{H}$ NMR $\left(400 \mathrm{MHz}, \mathrm{DMSO}-d_{6}\right) \delta \mathrm{ppm} 7.87(\mathrm{~d}, J=2.3 \mathrm{~Hz}, 1 \mathrm{H}) 7.73(\mathrm{dd}$, $J=8.6,2.3 \mathrm{~Hz}, 1 \mathrm{H}) 7.44(\mathrm{~d}, J=6.2 \mathrm{~Hz}, 1 \mathrm{H}) 7.36(\mathrm{~d}, J=8.8 \mathrm{~Hz}, 1 \mathrm{H}) 7.06(\mathrm{~d}, J=6.2 \mathrm{~Hz}, 1 \mathrm{H}) 4.05$ (d, J=6.9 Hz, 2 H) 3.79 - $3.85(\mathrm{~m}, 2 \mathrm{H}) 2.66(\mathrm{~s}, 3 \mathrm{H}) 1.55-1.66(\mathrm{~m}, 2 \mathrm{H}) 1.24-1.37$ (m, $3 \mathrm{H}) 0.91$ (t, $J=7.4 \mathrm{~Hz}, 3 \mathrm{H}) 0.55-0.69(\mathrm{~m}, 2 \mathrm{H}) 0.33-0.46(\mathrm{~m}, 2 \mathrm{H}) ; 1 \mathrm{H}$ exchanged (chlorohydrate form).

\section{Synthesis of intermediates 15 a-d (Procedures A, B, C and D):}

\section{Synthesis of the intermediate 7-butyl-3-chloro-[1,2,4]triazolo[4,3-a]pyrazin-8-one (16).}
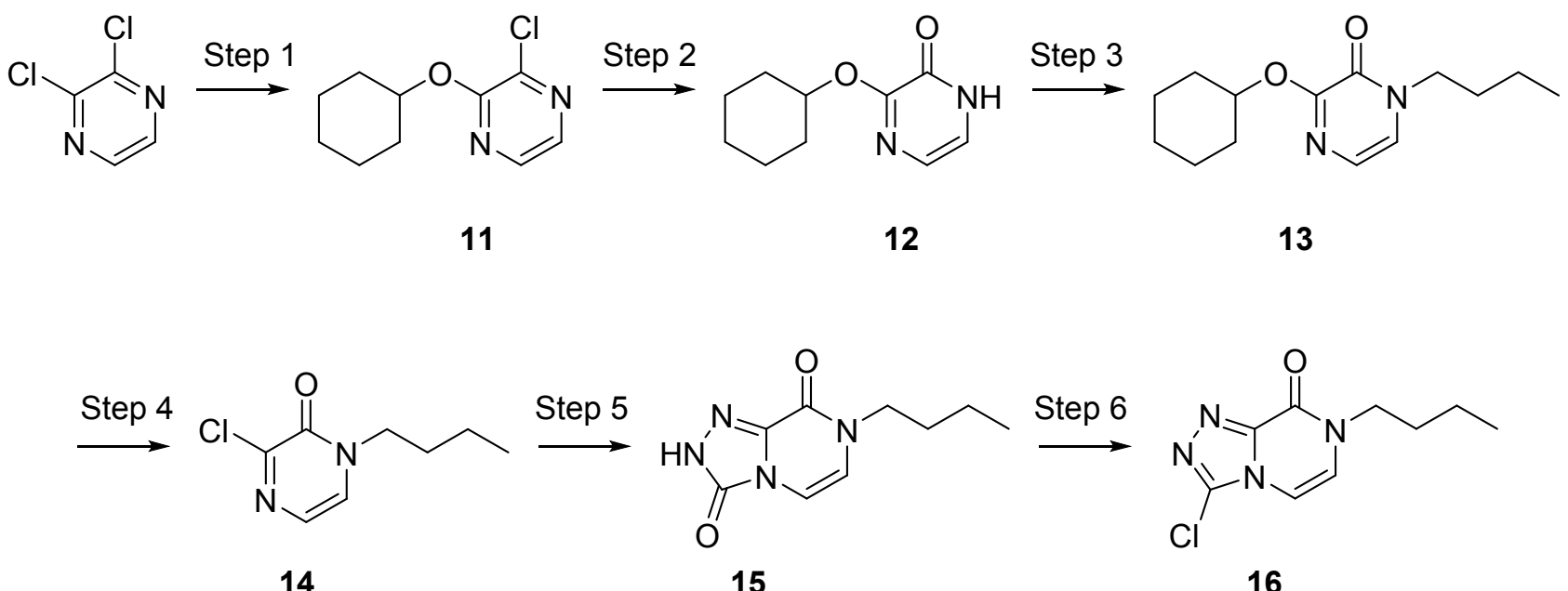

Step 1: $\mathrm{NaH}$ (2 g, $50 \mathrm{mmol}$ ) was added to a stirred solution of cyclohexanol (5.4 mL, $50 \mathrm{mmol}$, $0.96 \mathrm{~g} / \mathrm{mL})$ in 1,2 -dimethoxyethane $(50 \mathrm{~mL})$ at $0{ }^{\circ} \mathrm{C}$. The mixture was stirred at $0{ }^{\circ} \mathrm{C}$ for $10 \mathrm{~min}$, then 2,3-dichloropyridazine (5 g, $34 \mathrm{mmol})$ was added. The mixture was heated in a sealed tube at reflux for $30 \mathrm{~min}$. The mixture was cooled to rt. and diluted with water and extracted with AcOEt (3x $10 \mathrm{~mL})$, the organic layer was separated and dried over $\mathrm{Na}_{2} \mathrm{SO}_{4}$, filtered, concentrated in vacuo. 
The residue thus obtained was used without any further purification to yield intermediate $\mathbf{1 1}$ (6.5 g, 90\%) as oil. LC-MS m/z: calculated for $\mathrm{C}_{10} \mathrm{H}_{13} \mathrm{ClN}_{2} \mathrm{O}[\mathrm{M}+\mathrm{H}]+213.1$ found $213.2[\mathrm{M}+\mathrm{H}]+$. Step 2: $\mathrm{NaOH}(3 \mathrm{M}$ in water) $(37,6 \mathrm{~mL}, 112.8 \mathrm{mmol})$, was added to stirred solution of $11(6 \mathrm{~g}$, $28.21 \mathrm{mmol})$ in DMSO $(10 \mathrm{~mL})$ at $\mathrm{rt}$. The mixture was heated at $90{ }^{\circ} \mathrm{C}$ for $2 \mathrm{~h}$. The mixture was cooled to rt. and diluted with water and extracted with AcOEt $(3 \times 10 \mathrm{~mL})$, the organic layer was separated and dried over $\mathrm{Na}_{2} \mathrm{SO}_{4}$, filtered, concentrated in vacuo. The residue thus obtained was purified by flash chromatography (silica, AcOEt/Hept 0/100 to 30/70). The desired fractions were collected and concentrated in vacuo to yield intermediate $12(2.5 \mathrm{~g}, 45 \%)$ as oil. LC-MS m/z: calculated for $\mathrm{C}_{10} \mathrm{H}_{14} \mathrm{~N}_{2} \mathrm{O}_{2}[\mathrm{M}+\mathrm{H}]+195.1$ found $195.21[\mathrm{M}+\mathrm{H}]+$.

Step 3: 1-Bromobutane $(0.3 \mathrm{~mL}, 2.83 \mathrm{mmol}, 1.27 \mathrm{~g} / \mathrm{mL})$ was added to a solution of $\mathbf{1 2}(0.5 \mathrm{~g}, 2.57$ $\mathrm{mmol})$ and $\mathrm{K}_{2} \mathrm{CO}_{3}(0.53 \mathrm{~g}, 3.86 \mathrm{mmol})$ in $\mathrm{MeCN}(1 \mathrm{~mL})$ at $\mathrm{rt}$. The mixture was heated under MW irradiation at $140^{\circ} \mathrm{C}$ for $40 \mathrm{~min}$. The mixture was filtered through celite and concentrated in vacuo. The residue thus obtained was purified by flash chromatography (silica, $7 \mathrm{~N} \mathrm{NH}_{3}$ in $\mathrm{MeOH} / \mathrm{DCM}$ from $0 / 100$ to $5 / 95$ ). The desired fractions were collected and concentrated in vacuo to yield intermediate $13(0.5 \mathrm{~g}, 77 \%)$ as white solid. LC-MS m/z: calculated for $\mathrm{C}_{14} \mathrm{H}_{22} \mathrm{~N}_{2} \mathrm{O}_{2}[\mathrm{M}+\mathrm{H}]+$ 251.1 found $251.21[\mathrm{M}+\mathrm{H}]+$.

Step 4: $\mathrm{POCl}_{3}(2.6 \mathrm{~mL}, 27.96 \mathrm{mmol}, 1.645 \mathrm{~g} / \mathrm{mL})$ was added to a solution of $\mathbf{1 3}(2 \mathrm{~g}, 7.99 \mathrm{mmol})$ in DCM $(5 \mathrm{~mL})$ at $\mathrm{rt}$. The mixture was heated under MW irradiation at $150{ }^{\circ} \mathrm{C}$ for $20 \mathrm{~min}$. The mixture was diluted with water and extracted with DCM $(3 \times 3 \mathrm{~mL})$, the organic layer was separated and dried over $\mathrm{Na}_{2} \mathrm{SO}_{4}$, filtered, concentrated in vacuo. The residue thus obtained was purified by flash chromatography (silica, $\mathrm{MeOH}$ in DCM from $0 / 100$ to $5 / 95$ ). The desired fractions were collected and concentrated in vacuo to yield intermediate $14(0.9 \mathrm{~g}, 60 \%)$ as transparent oil. LC-MS m/z: calculated for $\mathrm{C}_{8} \mathrm{H}_{11} \mathrm{ClN}_{2} \mathrm{O}[\mathrm{M}+\mathrm{H}]+187.1$ found $187.2[\mathrm{M}+\mathrm{H}]+$. 
Step 5: Ethyl carbazate $(2.2 \mathrm{~g}, 31.2 \mathrm{mmol})$ was added to a solution of $\mathbf{1 4}(5.3 \mathrm{~g}, 28.4 \mathrm{mmol})$ in propionitrile $(20 \mathrm{~mL})$ at $\mathrm{rt}$. The mixture was heated under $\mathrm{MW}$ irradiation at $190{ }^{\circ} \mathrm{C}$ for $30 \mathrm{~min}$. The mixture was filtered and the solid was triturated with $\mathrm{Et}_{2} \mathrm{O}$ to yield intermediate 15 (6.4 g, $86.6 \%$ ) as solid. LC-MS m/z: calculated for $\mathrm{C}_{9} \mathrm{H}_{12} \mathrm{~N}_{4} \mathrm{O}_{2}[\mathrm{M}+\mathrm{H}]+209.1$ found $209.21[\mathrm{M}+\mathrm{H}]+$. ${ }^{1} \mathrm{H}$ NMR $\left(500 \mathrm{MHz}, \mathrm{DMSO}-d_{6}\right) \delta$ ppm $12.85(\mathrm{~s}, 1 \mathrm{H}) 6.97(\mathrm{~d}, J=6.1 \mathrm{~Hz}, 1 \mathrm{H}) 6.83$ (d, J=6.1 Hz, 1 H) 3.77 (t, $J=7.2 \mathrm{~Hz}, 2 \mathrm{H}) 1.58$ (quin, $J=7.4 \mathrm{~Hz}, 2 \mathrm{H}) 1.28(\mathrm{dq}, J=15.0,7.4 \mathrm{~Hz}, 2 \mathrm{H}) 0.89$ (t, $J=7.4$ $\mathrm{Hz}, 3 \mathrm{H})$.

Step 6: $\mathrm{POCl}_{3}(15 \mathrm{~mL}, 161 \mathrm{mmol}, 1.645 \mathrm{~g} / \mathrm{mL})$ was added to 15 (6 g, $\left.21.6 \mathrm{mmol}\right)$. The mixture was heated at $110^{\circ} \mathrm{C}$ for $22 \mathrm{~h}$. The mixture was evaporated in vacuo and the crude was diluted with AcOEt and washed with of $\mathrm{NaHCO}_{3}$ (aqueous sat. sol.). The organic layer was separated, dried over $\mathrm{Na}_{2} \mathrm{SO}_{4}$, filtered, concentrated in vacuo. The residue thus obtained was purified by flash chromatography (silica, AcOEt in DCM from 0/100 to 20/80). The desired fractions were collected and concentrated in vacuo to yield intermediate 16 (2.3 g, $35 \%)$ as transparent oil. LC-MS m/z: calculated for $\mathrm{C}_{9} \mathrm{H}_{11} \mathrm{ClN}_{4} \mathrm{O}[\mathrm{M}+\mathrm{H}]+227.1$ found $227.2[\mathrm{M}+\mathrm{H}]+.{ }^{1} \mathrm{H} \mathrm{NMR}\left(400 \mathrm{MHz}, \mathrm{CDCl}_{3}\right) \delta$ ppm $7.03(\mathrm{~d}, J=6.0 \mathrm{~Hz}, 1 \mathrm{H}) 6.77(\mathrm{~d}, J=6.0 \mathrm{~Hz}, 1 \mathrm{H}) 3.94-4.01(\mathrm{~m}, 2 \mathrm{H}) 1.68-1.81(\mathrm{~m}, 2 \mathrm{H}) 1.34$ - $1.46(\mathrm{~m}, 2 \mathrm{H}) 0.97$ (t, $J=7.3 \mathrm{~Hz}, 3 \mathrm{H})$.

\section{Synthesis of the intermediate 3-butylimidazo[2,1-f][1,2,4]triazin-4-one (19)}

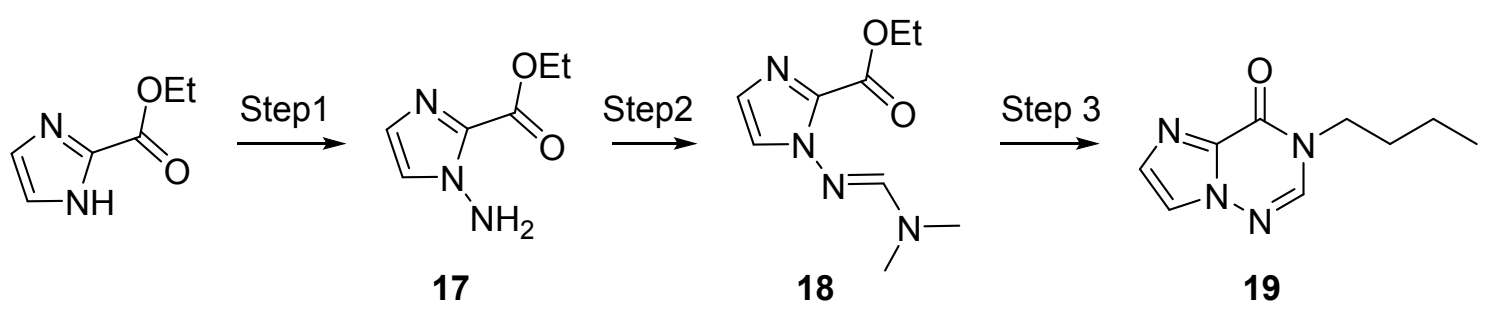


Step 1: o-diphenylphosphinylhydroxylamine $(0,05 \mathrm{~g}, 0.214 \mathrm{mmol})$ was added to a solution of ethyl $1 H$-imidazole-2-carboxylate $(0.02 \mathrm{~g}, 0.142 \mathrm{mmol})$ and $\mathrm{Cs}_{2} \mathrm{CO}_{3}(0.093 \mathrm{~g}, 0.285 \mathrm{mmol})$ in DMF (5 $\mathrm{mL}$ ) at rt. The mixture was stirred at rt $20 \mathrm{~min}$. The mixture was diluted with water and extracted with DCM $(3 \times 3 \mathrm{~mL})$, the organic layer was separated and dried over $\mathrm{Na}_{2} \mathrm{SO}_{4}$, filtered, concentrated in vacuo to yield intermediate $17(0.022 \mathrm{~g}, 99 \%)$ as oil. LC-MS m/z: calculated for $\mathrm{C}_{6} \mathrm{H}_{9} \mathrm{~N}_{3} \mathrm{O}_{2}[\mathrm{M}+\mathrm{H}]+156.1$ found $156.2[\mathrm{M}+\mathrm{H}]+$.

Step 2: N,N-Dimethylformamide dimethyl acetal $(0.619 \mathrm{~mL}, 4.663 \mathrm{mmol}, 0.897 \mathrm{~g} / \mathrm{mL})$ was added to a solution of $17(0.603 \mathrm{~g}, 3.88 \mathrm{mmol})$ in propionitrile $(10 \mathrm{~mL})$ at $\mathrm{rt}$. The mixture was heated under MW irradiation at $120^{\circ} \mathrm{C}$ for $15 \mathrm{~min}$. The mixture was concentrated in vacuo to yield intermediate $18(0.8 \mathrm{~g}, 97 \%)$ as solid. LC-MS m/z: calculated for $\mathrm{C}_{9} \mathrm{H}_{14} \mathrm{~N}_{4} \mathrm{O}_{2}[\mathrm{M}+\mathrm{H}]+211.1$ found $211.21[\mathrm{M}+\mathrm{H}]+$.

Step3: 1-Butylamine $(0.71 \mathrm{~mL}, 7.09 \mathrm{mmol}, 0.74 \mathrm{~g} / \mathrm{mL})$ was added to a solution of $\mathbf{1 8}(0.74 \mathrm{~g}, 3.54$ mmol) in propionitrile $(17 \mathrm{~mL})$ at $\mathrm{rt}$. The mixture was heated under $\mathrm{MW}$ irradiation at $180{ }^{\circ} \mathrm{C}$ for 50 min. The mixture was concentrated in vacuo. The residue thus obtained was purified by flash chromatography (silica, $\mathrm{MeOH}$ in DCM from 0/100 to 5/95). The desired fractions were collected and concentrated in vacuo to yield intermediate $19(0.26 \mathrm{~g}, 38.4 \%)$ as yellow solid. LC-MS m/z: calculated for $\mathrm{C} 9 \mathrm{H} 12 \mathrm{~N} 4 \mathrm{O}[\mathrm{M}+\mathrm{H}]+192.1$ found $192.21[\mathrm{M}+\mathrm{H}]+.{ }^{1} \mathrm{H}$ NMR $\left(500 \mathrm{MHz}, \mathrm{CDCl}_{3}\right) \delta$ ppm $7.69(\mathrm{~s}, 1 \mathrm{H}) 7.59$ (d, J=0.9 Hz, $1 \mathrm{H}) 7.55(\mathrm{~s}, 1 \mathrm{H}) 3.98$ (t, $J=7.4 \mathrm{~Hz}, 2 \mathrm{H}) 1.73-1.81$ (m, 2 H) $1.41(\mathrm{dq}, J=15.1,7.5 \mathrm{~Hz}, 2 \mathrm{H}) 0.97(\mathrm{t}, J=7.4 \mathrm{~Hz}, 3 \mathrm{H})$. 


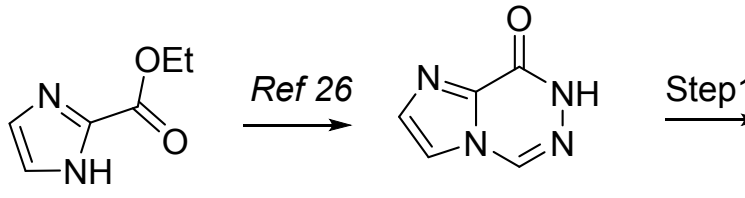

20

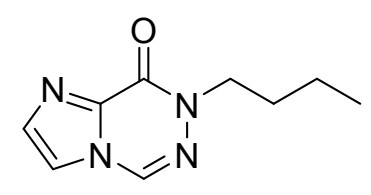

21

Step 1: $\mathrm{NaH}$ (60\% dispersion in mineral oil) $(0.092 \mathrm{~g}, 0.231 \mathrm{mmol})$ was added to a solution of 20 $(0.03 \mathrm{~g}, 0.22 \mathrm{mmol})$ in $\mathrm{DME}(0.5 \mathrm{~mL})$ and $\mathrm{DMF}(0.125 \mathrm{~mL})$ at $0{ }^{\circ} \mathrm{C}$. The mixture was stirred for $10 \mathrm{~min}$, then $\operatorname{LiBr}(0.038 \mathrm{~g}, 0.44 \mathrm{mmol})$ was added and the mixture was stirred for $15 \mathrm{~min}$ at $\mathrm{rt}$ then 1-iodobutane $(0.050 \mathrm{~mL}, 0.44 \mathrm{mmol}, 1.617 \mathrm{~g} / \mathrm{mL})$ was added. The mixture was heated under MW irradiation at $150{ }^{\circ} \mathrm{C}$ for $5 \mathrm{~min}$. Then, the mixture was poured into brine and extracted with AcOEt. The organic layer was separated, dried over $\mathrm{Na}_{2} \mathrm{SO}_{4}$, and concentrated in vacuo. The residue thus obtained was purified by flash chromatography (silica, $7 \mathrm{~N} \mathrm{NH}_{3}$ in $\mathrm{MeOH} / \mathrm{DCM}$ from $0 / 100$ to $5 / 95)$. The desired fractions were collected and concentrated in vacuo to yield intermediate $21(0.015 \mathrm{~g}, 35 \%)$ as white solid. LC-MS m/z: calculated for $\mathrm{C}_{9} \mathrm{H}_{12} \mathrm{~N}_{4} \mathrm{O}[\mathrm{M}+\mathrm{H}]+$ 193.1 found $193.3[\mathrm{M}+\mathrm{H}]+.{ }^{1} \mathrm{H}$ NMR $\left(400 \mathrm{MHz}, \mathrm{CDCl}_{3}\right) \delta \mathrm{ppm} 8.21(\mathrm{~s}, 1 \mathrm{H}) 7.61(\mathrm{~d}, J=1.2 \mathrm{~Hz}$, $1 \mathrm{H}) 7.46(\mathrm{~d}, J=1.2 \mathrm{~Hz}, 1 \mathrm{H}) 4.11-4.17(\mathrm{~m}, 2 \mathrm{H}) 1.75-1.83(\mathrm{~m}, 2 \mathrm{H}) 1.39$ (dq, $J=15.1,7.5 \mathrm{~Hz}, 2$ H) $0.95(\mathrm{t}, J=7.3 \mathrm{~Hz}, 3 \mathrm{H})$.

Synthesis of the intermediate 3-butyl-7-methyl-pyrazolo[1,5-a][1,3,5]triazin-4-one (24) 


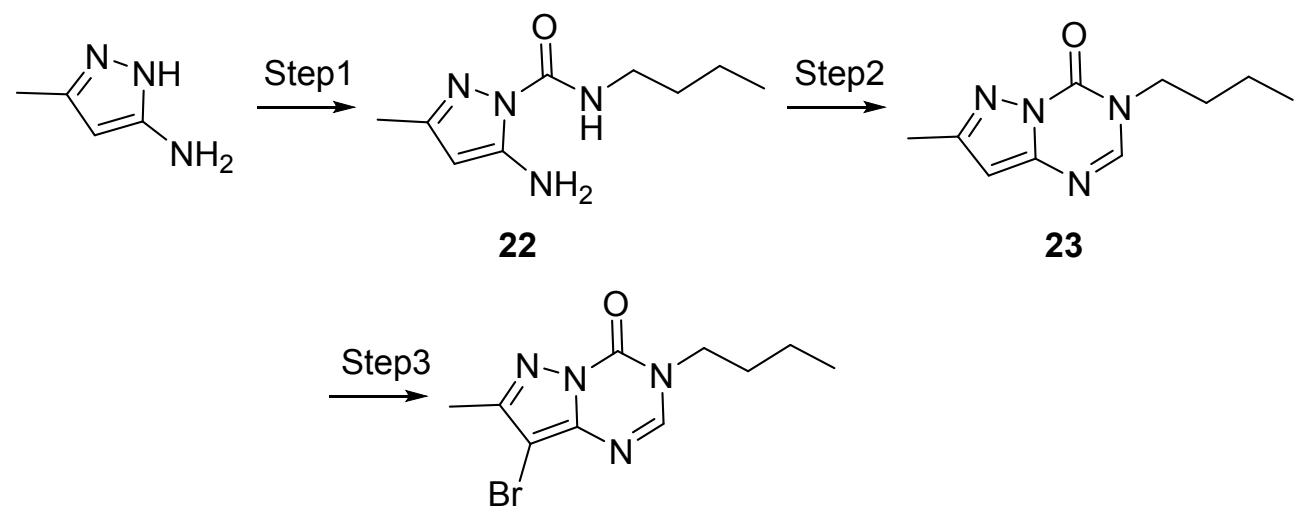

24

Step 1: DIPEA $(22.18 \mathrm{~mL}, 128.71 \mathrm{mmol}, 0.75 \mathrm{~g} / \mathrm{mL})$ was added to a solution of 3-amino-5methylpyrazole (5 g, $51.48 \mathrm{mmol})$, butyl isocyanate $(5.61 \mathrm{~g}, 56.63 \mathrm{mmol})$ in acetone $(60 \mathrm{~mL})$ at rt. The mixture was stirred at $50^{\circ} \mathrm{C}$ for $2 \mathrm{~h}$. The mixture was cooled and evaporated in vacuo. The residue thus obtained was purified by flash chromatography (silica, Heptane in AcOEt from 0/100 to 30/70). The desired fractions were collected and concentrated in vacuo to yield intermediate $\mathbf{2 2}$ (9 g, 89\%) as yellow oil. LC-MS m/z: calculated for $\mathrm{C}_{9} \mathrm{H}_{16} \mathrm{~N}_{4} \mathrm{O}[\mathrm{M}+\mathrm{H}]+197.1$ found $197.3[\mathrm{M}+$ $\mathrm{H}]+$.

Step 2: Triethyl orthoformate $(17.98 \mathrm{~mL}, 101.91 \mathrm{mmol}, 0.84 \mathrm{~g} / \mathrm{mL})$ was added to a solution of 22 (8 g, $40.76 \mathrm{mmol})$ in DMF $(6 \mathrm{~mL})$ at $\mathrm{rt}$. The mixture was heated under MW irradiation at $160{ }^{\circ} \mathrm{C}$ for $40 \mathrm{~min}$. The mixture was cooled and evaporated in vacuo. The residue thus obtained was purified by flash chromatography (silica, $\mathrm{MeOH}$ in DCM from $0 / 100$ to 5/95). The desired fractions were collected and concentrated in vacuo to yield intermediate $23(3.2 \mathrm{~g}, 38 \%)$ as solid. LC-MS m/z: calculated for $\mathrm{C}_{10} \mathrm{H}_{14} \mathrm{~N}_{4} \mathrm{O}[\mathrm{M}+\mathrm{H}]+207.1$ found $207.3[\mathrm{M}+\mathrm{H}]+$.

Step 3: NBS (0.76 g, $4.268 \mathrm{mmol})$ was added to a solution $24(0.81 \mathrm{~g}, 3.879 \mathrm{mmol})$ in DMF (2 $\mathrm{mL})$ at $\mathrm{rt}$. The mixture was stirred at $50{ }^{\circ} \mathrm{C}$ rt for $1 \mathrm{~h}$. The crude treated with aqueous saturated solution of $\mathrm{NaHCO}_{3}$ and extracted with DCM $(3 \times 5 \mathrm{ml})$ the combined organic phases were concentrated in vacuo to afford an orange solid which was washed with DIPE yield intermediate 
$26(0.7 \mathrm{~g}, 63 \%)$ as solid. LC-MS m/z: calculated for $\mathrm{C}_{10} \mathrm{H}_{13} \mathrm{BrN}_{4} \mathrm{O}[\mathrm{M}+\mathrm{H}]+285.1$ found $285.3[\mathrm{M}$ + H]+. ${ }^{1} \mathrm{H}$ NMR $\left(400 \mathrm{MHz}, \mathrm{CDCl}_{3}\right) \delta \mathrm{ppm} 7.79(\mathrm{~s}, 1 \mathrm{H}) 4.01(\mathrm{t}, J=7.3 \mathrm{~Hz}, 2 \mathrm{H}) 2.45(\mathrm{~s}, 3 \mathrm{H}) 1.73$

- 1.85 (m, 2 H) 1.41 (dq, $J=15.2,7.4 \mathrm{~Hz}, 2 \mathrm{H}) 0.98(\mathrm{t}, J=7.4 \mathrm{~Hz}, 3 \mathrm{H})$.

Synthesis of the intermediate 3-[3-chloro-4-(cyclopropylmethoxy)phenyl]-1-methyl-7H-

imidazo[1,5-a]pyrazin-8-one (28)

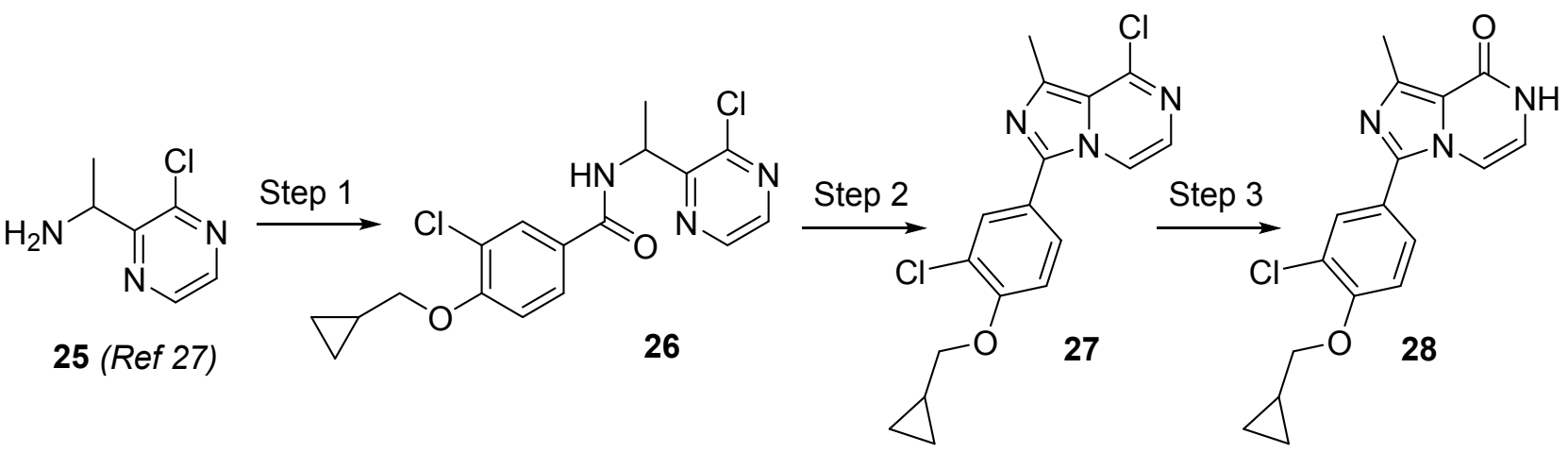

Step 1: HATU $(0.86 \mathrm{~g}, 2.27 \mathrm{mmol})$ was added to a solution of $\mathbf{2 5}(0.33 \mathrm{~g}, 2.06 \mathrm{mmol})$, 3-chloro-4-

(cyclopropylmethoxy)-benzoic acid (0.52g, 2.27 mmol; C.A.S. 856165-89-4), DIPEA (1.42 mL, $8.25 \mathrm{mmol}, 0.75 \mathrm{~g} / \mathrm{mL})$ in DMF $(10 \mathrm{~mL})$ at rt. The mixture was stirred at $\mathrm{rt}$ for $24 \mathrm{~h}$. Water $(5 \mathrm{~mL})$ was added and the crude was extracted with DCM $(2 \times 10 \mathrm{~mL})$, the organic layers were collected dried over $\mathrm{Na}_{2} \mathrm{SO}_{4}$, and concentrated in vacuo. The residue thus obtained was purified by flash chromatography (silica, $7 \mathrm{~N} \mathrm{NH}_{3}$ in $\mathrm{MeOH} / \mathrm{DCM}$ from 0/100 to 5/95). The desired fractions were collected and concentrated in vacuo to yield intermediate $26(0.6 \mathrm{~g}, 79 \%)$ as oil. LC-MS m/z: calculated for $\mathrm{C}_{17} \mathrm{H}_{17} \mathrm{Cl}_{2} \mathrm{~N}_{3} \mathrm{O}_{2}[\mathrm{M}+\mathrm{H}]+366.1$ found $366.3[\mathrm{M}+\mathrm{H}]+.{ }^{1} \mathrm{H}$ NMR $\left(400 \mathrm{MHz}, \mathrm{CDCl}_{3}\right)$ $\delta$ ppm $8.49(\mathrm{~d}, J=2.3 \mathrm{~Hz}, 1 \mathrm{H}) 8.35(\mathrm{~d}, J=2.5 \mathrm{~Hz}, 1 \mathrm{H}) 7.86(\mathrm{~d}, J=2.3 \mathrm{~Hz}, 1 \mathrm{H}) 7.73(\mathrm{dd}, J=8.6,2.3$ $\mathrm{Hz}, 1 \mathrm{H}) 7.38$ (br d, $J=7.6 \mathrm{~Hz}, 1 \mathrm{H}) 6.94(\mathrm{~d}, J=8.8 \mathrm{~Hz}, 1 \mathrm{H}) 5.74$ (quin, $J=7.0 \mathrm{~Hz}, 1 \mathrm{H}) 3.94$ (d, 
$J=6.7 \mathrm{~Hz}, 2 \mathrm{H}) 1.58(\mathrm{br} \mathrm{d}, J=6.7 \mathrm{~Hz}, 3 \mathrm{H}) 1.27-1.38(\mathrm{~m}, 1 \mathrm{H}) 0.60-0.74(\mathrm{~m}, 2 \mathrm{H}) 0.34$ - 0.46 (m, $2 \mathrm{H}$ ).

Step 2: $\mathrm{POCl}_{3}(0.44 \mathrm{~mL}, 4.77 \mathrm{mmol}, 1.64 \mathrm{~g} / \mathrm{mL})$ was added to a solution of $\mathbf{2 6}(0.7 \mathrm{~g}, 1.91 \mathrm{mmol})$ in Toluene $(10 \mathrm{~mL})$ at $\mathrm{rt}$. The mixture was stirred at reflux for $4 \mathrm{~h}$. The mixture was cooled and concentrated in vacuo. A saturated solution of $\mathrm{NaHCO}_{3}(7 \mathrm{ml})$ was added followed DCM $(20 \mathrm{~mL})$. The mixture was stirred for $30 \mathrm{~min}$. and then extracted with DCM $(2 \times 10 \mathrm{~mL})$, the organic fractions were collected dried over $\mathrm{Na}_{2} \mathrm{SO}_{4}$, and concentrated in vacuo to yield intermediate $27(0.35 \mathrm{~g}$, $52 \%$ ) as oil. LC-MS m/z: calculated for $\mathrm{C}_{17} \mathrm{H}_{15} \mathrm{Cl}_{2} \mathrm{~N}_{3} \mathrm{O}[\mathrm{M}+\mathrm{H}]+348.2$ found $348.3[\mathrm{M}+\mathrm{H}]+$.

Step 3: $\mathrm{NaOH}(1 \mathrm{M}$ in $\mathrm{H} 2 \mathrm{O})(5 \mathrm{~mL}, 5 \mathrm{mmol})$ was added to a solution of $27(0.32 \mathrm{~g}, 0.92 \mathrm{mmol})$ in DMSO $(5 \mathrm{~mL})$ at $\mathrm{rt}$. The mixture was heated $120{ }^{\circ} \mathrm{C}$ for $4 \mathrm{~h}$. The mixture was cooled at $\mathrm{rt}$ and acidified with $\mathrm{HCl}(2 \mathrm{~N})$ followed DCM $(20 \mathrm{~mL})$. The mixture was stirred for $30 \mathrm{~min}$. and then extracted with DCM $(2 \times 10 \mathrm{~mL})$, the organic fractions were collected dried over $\mathrm{Na}_{2} \mathrm{SO}_{4}$, and concentrated in vacuo to yield intermediate 28 (0.25 g, $82.5 \%)$. LC-MS m/z: calculated for $\mathrm{C}_{17} \mathrm{H}_{16} \mathrm{ClN}_{3} \mathrm{O}_{2}[\mathrm{M}+\mathrm{H}]+330.1$ found $330.2[\mathrm{M}+\mathrm{H}]+$. 
Analytical methods

1. LCMS methods

For (LC)MS-characterization of the compounds of the present invention, the following methods were used.

- General procedure A: 
The HPLC measurement was performed using an HP 1100 (Agilent Technologies) system comprising a pump (quaternary or binary) with degasser, an autosampler, a column oven, a diodearray detector (DAD) and a column as specified in the respective methods. The MS detector (SQD, MSD) was configured with an electrospray ionization source. Nitrogen was used as the nebulizer gas. The source temperature was maintained at $140{ }^{\circ} \mathrm{C}$. Data acquisition was performed with MassLynx-Openlynx software.

A1: Mass spectra were acquired on a single quadrupole SQD detector by scanning from 100 to 1000 umas in 0.1 second using an inter-channel delay of 0.08 second. The capillary needle voltage was $3.0 \mathrm{kV}$. The cone voltage was $20 \mathrm{~V}$ and $50 \mathrm{~V}$ for positive ionization mode and $30 \mathrm{~V}$ for negative ionization mode.

A2: Mass spectra were acquired on a single quadrupole MSD detector by scanning from 100 to 1000 in 0.99 seconds, step size of 0.30 and peak width of 0.10 minutes. The capillary needle voltage was $1.0 \mathrm{kV}$; the fragmentor voltage was $70 \mathrm{~V}$ for positive and negative ionization modes.

\section{Method 1:}


In addition to the general procedure A1: Reversed phase HPLC was carried out on an Eclipse Plus$\mathrm{C} 18$ column $(3.5 \mu \mathrm{m}, 2.1 \times 30 \mathrm{~mm})$ from Agilent, with a flow rate of $1.0 \mathrm{ml} / \mathrm{min}$, at $60^{\circ} \mathrm{C}$ without split to the MS detector. The gradient conditions used are: $95 \%$ A $\left(6.5 \mathrm{mM} \mathrm{NH}_{4} \mathrm{AcO}\right.$ in $\mathrm{H}_{2} \mathrm{O} / \mathrm{MeCN}$ 95/5), $5 \%$ B (mixture of $\mathrm{MeCN} / \mathrm{MeOH}, 1 / 1$ ), kept 0.2 minutes, to $100 \%$ B in 3.0 minutes, kept till 3.15 minutes and equilibrated to initial conditions at 3.30 minutes until 5.0 minutes. The injection volume used was $2 \mu \mathrm{l}$.

\section{Method 2:}

In addition to the general procedure A1: Reversed phase HPLC was carried out on an Eclipse PlusC18 column $(3.5 \mu \mathrm{m}, 2.1 \times 30 \mathrm{~mm})$ from Agilent, with a flow rate of $1.0 \mathrm{ml} / \mathrm{min}$, at $60^{\circ} \mathrm{C}$ without split to the MS detector. The gradient conditions used are: $95 \% \mathrm{~A}\left(6.5 \mathrm{mM} \mathrm{NH} \mathrm{NH}_{4} \mathrm{AcO}\right.$ in $\mathrm{H}_{2} \mathrm{O} / \mathrm{MeCN}$ 95/5), $5 \% \mathrm{~B}$ (mixture of $\mathrm{MeCN} / \mathrm{MeOH}, 1 / 1$ ), to $100 \% \mathrm{~B}$ in 5.0 minutes, kept till 5.15 minutes and equilibrated to initial conditions at 5.30 minutes until 7.0 minutes. The injection volume used was $2 \mu \mathrm{l}$. The cone voltage was $20 \mathrm{~V}$ for positive ionization mode and $30 \mathrm{~V}$ for negative ionization mode.

\section{- General procedure B:}


The UPLC (Ultra Performance Liquid Chromatography) measurement was performed using an Acquity UPLC (Waters) system comprising a sampler organizer, a binary pump with degasser, a four column's oven, a diode-array detector (DAD) and a column as specified in the respective methods. Flow from the column was brought to the MS spectrometer. The MS detector was configured with an electrospray ionization source. Mass spectra were acquired on a single quadrupole SQD detector by scanning from 100 to 1000 in 0.1 second using an inter-channel delay of 0.08 second. The capillary needle voltage was $3.0 \mathrm{kV}$. The cone voltage was $25 \mathrm{~V}$ for positive ionization mode and $30 \mathrm{~V}$ for negative ionization mode. The source temperature was maintained at $140{ }^{\circ} \mathrm{C}$. Nitrogen was used as the nebulizer gas. Data acquisition was performed with MassLynx-Openlynx software.

\section{General procedure}

The GC measurement was performed using a 6890 Series Gas Chromatograph (Agilent Technologies) system comprising a 7683 Series injector and autosampler, a column oven and a column as specified in the respective methods below, coupled to a 5973N MSD Mass Selective Detector (single quadrupole, Agilent Technologies). The MS detector was configured with an electronic impact ionization source / chemical ionization source (EI/CI). EI low-resolution mass spectra were acquired by scanning from 50 to 550 at a rate of 14.29 scans/s. The source temperature 
was maintained at $230^{\circ} \mathrm{C}$. Helium was used as the nebulizer gas. Data acquisition was performed with Chemstation-Open Action software.

\section{Method EI-8}

In addition to the general procedure: GC was carried out on a J\&W HP-5MS column (20 m x 0.18 $\mathrm{mm}, 0.18 \mu \mathrm{m}$ ) from Agilent Technologies, with a flow rate of $0.7 \mathrm{ml} / \mathrm{min}$. The temperature gradient applied was: initial temperature $50^{\circ} \mathrm{C}$, hold for $0.8 \mathrm{~min}$, then a $60^{\circ} \mathrm{C} / \mathrm{min}$ ramp applied for $4.17 \mathrm{~min}$ until $300^{\circ} \mathrm{C}$ and hold for $3.0 \mathrm{~min}$ in a $8 \mathrm{~min}$ run. Front inlet temperature was $250^{\circ} \mathrm{C}$. Split injection mode was used, $0.2 \mu \mathrm{l}$ injection volume, with a 50/1 ratio into the GC/MS system.

\section{Biochemical assay}


Membrane preparation: $\mathrm{CHO}-$ cells were cultured to pre-confluence and stimulated with $5 \mathrm{mM}$ butyrate for $24 \mathrm{~h}$. Cells were then collected by scraping in PBS and cell suspension was centrifuged (10 min at 4000 RPM in benchtop centrifuge). Supernatant was discarded and pellet gently resuspended in $50 \mathrm{mM}$ Tris- $\mathrm{HCl}, \mathrm{pH} 7.4$ by mixing with a vortex and pipetting up and down. The suspension was centrifuged at 16,000 RPM (Sorvall RC-5C plus rotor SS-34) for 10 minutes and the supernatant discarded. The pellet was homogenized in $5 \mathrm{mM}$ Tris- $\mathrm{HCl}, \mathrm{pH} 7.4$ using an ultraturrax homogenizer and centrifuged again $\left(18,000 \mathrm{RPM}, 20 \mathrm{~min}, 4{ }^{\circ} \mathrm{C}\right)$. The final pellet was resuspended in $50 \mathrm{mM}$ Tris- $\mathrm{HCl}, \mathrm{pH} 7.4$ and stored at $-80{ }^{\circ} \mathrm{C}$ in appropriate aliquots before use. Protein concentration was determined by the Bradford method (Bio-Rad, USA) with bovine serum albumin as standard.

[35S]GTPYS Binding Assay. For $\left[{ }^{35} \mathrm{~S}\right] \mathrm{GTP} y \mathrm{~S}$ measurements, compound and glutamate were diluted in buffer containing $10 \mathrm{mM}$ HEPES acid, $10 \mathrm{mM}$ HEPES salt, $\mathrm{pH}$ 7.4, containing $100 \mathrm{mM}$ $\mathrm{NaCl}, 3 \mathrm{mM} \mathrm{MgCl}$, and $10 \mu \mathrm{M}$ GDP. Membranes were thawed on ice and diluted in the same buffer, supplemented with $14 \mu \mathrm{g} / \mathrm{mL}$ saponin (final assay concentration of $2 \mu \mathrm{g} / \mathrm{mL}$ saponin). Final assay mixtures contained $7 \mu \mathrm{g}$ of membrane protein and were preincubated with compound alone (determination of agonist effects) or together with an EC20 concentration $(4 \mu \mathrm{M})$ of glutamate 
(determination of PAM effects) for $30 \mathrm{~min}$ at $30{ }^{\circ} \mathrm{C} .\left[{ }^{35} \mathrm{~S}\right] \mathrm{GTP} Y \mathrm{~S}$ was added at a final concentration of $0.1 \mathrm{nM}$ and incubated for another $30 \mathrm{~min}$ at $30{ }^{\circ} \mathrm{C}$. Reactions were terminated by rapid filtration through Unifilter-96 GF/ B filter plates (Packard) using a 96-well Packard filtermate harvester. Filters were washed six times with ice-cold $10 \mathrm{mM} \mathrm{NaH}_{2} \mathrm{PO}_{4} / 10 \mathrm{mM} \mathrm{Na} 2 \mathrm{HPO}_{4}, \mathrm{pH} 7.4$, and filterbound radioactivity was counted in a microplate scintillation and luminescence counter from Packard.

Data analysis: The concentration-response curves of representative compounds of the present invention -obtained in the presence of $\mathrm{EC}_{20}$ of $\mathrm{mGluR2}$ agonist glutamate to determine positive allosteric modulation (PAM)- were generated using the Lexis software interface (developed at J\&J). Data were calculated as \% of the control glutamate response, defined as the maximal response that is generated upon addition of glutamate alone. Sigmoid concentration-response curves plotting these percentages versus the log concentration of the test compound were analyzed using non-linear regression analysis. The concentration producing half-maximal effect is then calculated as $\mathrm{EC}_{50} . \mathrm{E}_{\max }$ is defined as relative maximal effect (i.e. maximal \% effect relative to the control glutamate response). All compounds were tested in presence of mGluR2 agonist glutamate at a predetermined $\mathrm{EC}_{20}$ concentration, to determine positive allosteric modulation. $\mathrm{EC}_{50}$ values 
were calculated from a concentration-response experiment of at least 8 concentrations. If more experiments were performed, the average $\mathrm{EC}_{50}$ value is reported and error deviation was $<0.5$.

Selectivity panel

Ca2+ assays with human mGlu1, 3, 5, 7, or 8 receptor-expressing HEK 293 cells were performed as reported in Lavreysen et al. (2013), except for a slight change in the procedure for mGlu5: cells expressing the human mGlu5 receptor were seeded at 40,000 cells/well in MW384. Twenty-four hours after seeding, cells were incubated for $90 \mathrm{~min}$ in $\mathrm{Ca} 2+$ assay kit (Molecular Devices) dissolved in saline PBS supplemented with $5 \mathrm{mmol} / \mathrm{L}$ probenecid, pH 7.4 (f.c. $2.5 \mathrm{mmol} / \mathrm{L}$ probenecid as loading buffer was added on the cell layer without removal of medium) before measurements. Measurement of [35S]GTP $\gamma \mathrm{S}$ binding to membranes from $\mathrm{CHO}$ cells expressing the rat mGlu6 receptor and membranes from L929sA cells expressing the human mGlu4 receptor were conducted as described in Lavreysen et al. 2013. 